Supporting Information

\title{
Aptamer- and Antisense-Mediated Two-Dimensional Isolation of Specific Cancer Cell Subpopulations
}

Mahmoud Labib ${ }^{\dagger}$, Brenda Green ${ }^{\ddagger}$, Reza M. Mohamadi ${ }^{\dagger}$, Adam Mepham ${ }^{\ddagger}$, Sharif U. Ahmed $^{\dagger}$, Laili Mahmoudian ${ }^{\dagger}$, I-Hsin Chang $^{\dagger}$, Edward H. Sargent ${ }^{\S}$, Shana O. Kelley ${ }^{\dagger, \pm, \|, *}$

${ }^{\dagger}$ Department of Pharmaceutical Sciences, University of Toronto, Toronto, Ontario M5S 3M2, Canada, ${ }^{\ddagger}$ Institute for Biomedical and Biomaterials Engineering, University of Toronto, Toronto, Ontario M5S 3G4, Canada, ${ }^{\S}$ Department of Electrical \& Computer Engineering, University of Toronto, Toronto, Ontario M5S 1A8, Canada, "Department of Biochemistry, University of Toronto, Toronto, Ontario M5S 1A8, Canada

\section{INDEX}

\section{EXPERIMENTAL SECTION}

\section{TABLES}

Table S1. Sequence of the nucleic acids utilized in the experimental setup

\section{FIGURES}

Figure S1. The workstation setup for isolation of cancer cell subpopulations.

Figure S2. Closed (A) and opened (B) configuration of the valves within the microfluidic device.

Figure S3. Selection of an EpCAM specific aptamer with high capture efficiency for EpCAM-expressing cancer cells.

Figure S4. Verification of the binding of EpCAM specific aptamer, EpCAM1 to EpCAM expressing cells.

Figure S5. Evaluation of the effect of the spacer on the capture efficiency of EpCAM specific aptamer.

Figure S6. Selection of a HER2 specific aptamer with high capture efficiency for HER2-expressing cancer cells.

Figure S7. Optimization of the magnetic nanoparticles concentration and cell release format.

Figure S8. Effect of the magnetic nanoparticles concentration on the cell release efficiency.

Figure S9. Optimization of releasing agent concentration.

Figure S10. Aptamer-based capture of cells from unprocessed whole blood.

Figure S11. EpCAM1 aptamer based capture of cells from whole, red blood cell-depleted and leukocyte-depleted blood.

Figure S12. HER2-1 aptamer based capture of cells from whole, red blood cell-depleted and leukocyte -depleted blood.

Figure S13. Aptamer mediated 2D isolation of sixteen cell subpopulations from SKBR3 cells.

Figure S14. Aptamer mediated 2D isolation of sixteen cell subpopulations from MDA-MB-361 cells.

Figure S15. Flow cytometric analysis of SKBR3 subpopulations

Figure S16. Profiling of three breast cancer cell lines using Ap2D-CTC chip and flow cytometry.

Figure S17. Purity of the cancer cells isolated using Ap2D-CTC chip.

Figure S18. Specificity of the Ap2D-CTC chip.

Figure S19. Flow cytometric analysis of the collagen content of isolated cell subpopulaions.

Figure S20. Flow cytometric analysis of the EpCAM expression level of isolated cell subpopulations.

Figure S21. Viability of isolated cell subpopulations.

Figure S22. Proliferative capacity of isolated cell subpopulations.

Figure S23. Fluorescence microscope images of the isolated $\mathrm{CK}^{+} / \mathrm{DAPI}{ }^{+} / \mathrm{CD} 45^{-}$cell subpopulations from prostate cancer patient's blood. 


\section{EXPERIMENTAL SECTION}

Chip fabrication. Chips were fabricated using Poly(dimethoxysilane) (PDMS, Dow Chemical, US) soft-lithography. Masters were fabricated on silicon substrates and patterned in SU-8 3050 (Microchem, US). PDMS replicas were poured on masters and baked at $67{ }^{\circ} \mathrm{C}$ for $45 \mathrm{~min}$. After peeling the replicas, holes were pierced to connect the tubing. PDMS replicas were attached to no. 1 glass cover slips using a $30 \mathrm{~s}$ plasma treatment and left to bond overnight. This step allows for enhancing the bonding and making it irreversible by oxidizing both the replica and the cover in plasma discharge. Afterward, the silicon tubing were attached to the inlet and outlet of the device. Prior to use, devices were conditioned with $1 \%$ Pluoronic F68 (Sigma-Aldrich, US) in phosphate-buffered saline (PBS) for $1 \mathrm{~h}$, to reduce nonspecific adsorption. Each device was sandwiched between an array of N52 Nd FeB magnets (K\&J Magnetics, US, 1.5 $\mathrm{mm}$ by $8 \mathrm{~mm}$ ) with alternating polarity. A syringe pump (Chemyx, US) was used for the duration of the cell capture process. Importantly, the 16 zones used in the 2nd dimension capture were connected with external tubes. The cell subpopulations were released separately from each zone after disconnecting each zone from the former and latter zone.

Cell Culture. VCaP cells (ATCC CRL-2876) and MDA-MB-361 were cultured in DMEM medium (ATCC 30-2002). SKBR3 cells were cultured in McCoy's Medium Modified (ATCC 30-2007). U937 cells were cultured in RPMI-1640 medium (ATCC 30-2001). All media were supplemented with $10 \%$ FBS and cells were cultured at $37^{\circ} \mathrm{C}$ and $5 \% \mathrm{CO}_{2}$ in T75 flasks. Cells were harvested when they reached more than $70-80 \%$ confluence. Cell detachment from the culture dishes was performed using $5 \mathrm{~mL}$ of a non-enzymatic cell dissociation reagent (1X; MP Biomedicals, Solon, $\mathrm{OH}) 37^{\circ} \mathrm{C}$ for $10 \mathrm{~min}$. Noteworthy that the non-enzymatic solution was used instead of trypsin to avoid any damage to the extracellular domains of the membrane antigens. Prior to introduction into the fluidic device, the cells were filtered using a $40 \mu \mathrm{m}$ BD falcon cell strainer (Becton, Dickinson and Company, Franklin Lakes, $\mathrm{NJ}$ ).

Cell tagging with magnetic nanoparticle-labeled aptamers. Briefly, $100 \mu \mathrm{L}$ of $20 \mu \mathrm{M}$ of the apatmer solution in Dulbecco's phosphate-buffered saline (DPBS, Sigma-Aldrich, US) was first denatured for $5 \mathrm{~min}$ at $95^{\circ} \mathrm{C}$ then renatured on ice for $10 \mathrm{~min}$. Afterward, the aptamer solution was added to the wells of the microtitre plate and incubated with 1 $\mu \mathrm{L}$ of $10 \mathrm{mg} \mathrm{mL}^{-1}$ of streptavidin coated magnetic nanoparticles $(100 \mu \mathrm{m}$, Chemicell, US) for $1 \mathrm{~h}$ at room temp. Subsequently, the nanoparticles were deposited using a magnetic stand (Thermofisher, US) and washed twice with DPBS. Prior to loading into the fluidic device, the aptamer-labeled magnetic nanoparticles were incubated with the cells either in $1 \%$ BSA in DPBS or in blood for $1 \mathrm{~h}$ at room temp. Notably, magnetic nanoparticles were selected over microparticles to improve the cell capture efficiency, since their higher surface-to-volume could significantly improve the binding kinetics and allow for 
thousands of binding events per cell. ${ }^{1}$ In addition, magnetic nanoparticles possess higher colloidal stability than the microparticles. ${ }^{2}$ Furthermore, a nanoparticles/aptamer conjugate could significantly improve the cell capture efficiency since the nanoparticles could act as multivalent ligand scaffolds to assemble multiple aptamers on their surface. ${ }^{3,4}$ Hence, the aptamers could bind to the cells in a cooperative manner, resulting in enhanced capture efficiency. Control experiments were carried out using 20 $\mu \mathrm{L}$ of magnetic nanoneads labeled anti-EpCAM antibody (Miltenyi Biotec Inc., US), magnetic nanobeads labeled anti-HER2 antibody (Miltenyi Biotec Inc., US), biotin labeled anti-EGFR antibody (Abcam, US).

Cell staining and imaging. Captured cells were counted using fluorescence microscopy. Prior to staining, captured cells were fixed inside the chip using $100 \mu \mathrm{L}$ of $4 \%$ formaldehyde solution (Sigma-Aldrich, US) followed by $100 \mu \mathrm{L}$ of $0.2 \%$ Triton $\mathrm{X}-100$ (Sigma-Aldrich, US) for permeabilization. For staining, we used $100 \mu \mathrm{L}$ of the following reagents: allophycocyanin-labeled anti-cytokeratin antibody (APC-CK, Genetex GTX80205, US) and alexafluor 488-labeled anti-CD45 antibody (AF488-CD45, Invitrogen MHCD4520, US), and the nuclear stain, 4,6-diamidino-2-phenylindole (DAPI Prolong Gold reagent, Invitrogen, US). Antibodies (3 $\mu \mathrm{L}$ each) were prepared in $100 \mu \mathrm{L}$ PBS containing $1 \%$ BSA and $0.1 \%$ Tween20. DAPI (1 drop) was prepared in $1 \mathrm{~mL}$ of $1 \%$ BSA solution in PBS. All chips were stained for 60 min at a flow rate of $0.1 \mathrm{~mL} \mathrm{~h}^{-1}$. After staining chips were washed with $0.1 \%$ Tween 20 in PBS, dried and stored at $4{ }^{\circ} \mathrm{C}$. After immunostaining, chips were scanned using a Nikon Ti-E Eclipse microscope with an automated stage controller and a CMOS Camera (Andor Neo). The blue channel was used for DAPI staining, with a typical exposure time of 10-20 ms. The green channel was used for the AF488-CD45 staining, with a typical exposure time of 40-60 ms. The red channel was used for the APC-CK staining, with a typical exposure time of 100-200 ms. The exposure time was set individually for each chip and kept constant in the course of scanning. The imaging was qualitative in nature and hence the variation of exposure time between chips did not affect the results. Cells were counted by overlaying the bright field, red, blue, and green fluorescent images.

Cell capture from whole, red blood cell-depleted, and leukocyte-depleted blood. For whole blood analysis, 300 SKBR3 cells in $100 \mu \mathrm{L}$ of $1 \%$ BSA-DPBS were added to $825 \mu \mathrm{L}$ of fresh blood from a healthy donor with consent, followed by $75 \mu \mathrm{L}$ of mercaptoethanol (MCE). For red blood cell-depleted blood analysis, the red blood cells were separated from the previous mixture using Ficoll method. Subsequently, $5 \mathrm{~mL}$ of DPBS was added and the mixture was centrifuged for $5 \mathrm{~min}$ at $1,200 \mathrm{rpm}$. After discarding the supernatant, the cells were resuspended in $1 \mathrm{~mL}$ of $1 \%$ BSA in DPBS. For analysis of leukocyte-depleted blood, the cells/MCE/blood mixture was incubated with $50 \mu \mathrm{L}$ of either anti-CD15 (Miltenyi Biotec Inc., US) or anti-CD45 (Miltenyi Biotec Inc., US), for $30 \mathrm{~min}$ at room temp. Subsequently, the magnetic nanoparticles were 
separated using a magnetic stand (ThermoFisher Scientific, US) and the supernatant was used for analysis.

Culture of isolated cancer cell subpopulations. SKBR3 cell subpopulations retrieved from the sixteen zones were cultured in 12-well plates previously coated with $1 \mathrm{~mL}$ of $100 \mu \mathrm{g} \mathrm{mL}{ }^{-1}$ fluorescein isothiocyanate labeled collagen (FITC-collagen, Exalpha, US) over night. After adding the cells to the wells, $1 \mathrm{~mL}$ of McCoy's Medium Modified (ATCC $30-2007$ ), containing $10 \%$ FBS and $1 \%$ penicillin-streptomycin, was added to each well and the plates were incubated for $48 \mathrm{~h}$ at $37{ }^{\circ} \mathrm{C}$ and $5 \% \mathrm{CO}_{2}$. Afterward, cells were released using $1 \mathrm{mg} \mathrm{mL}^{-1}$ collagenase enzyme (Sigma-Aldrich, US) for $15 \mathrm{~min}$ at $37^{\circ} \mathrm{C}$.

Flow cytometric analysis of isolated cell subpopulations. Enriched cell subpopulations were fixed with $4 \%$ formaldehyde solution and incubated with Alexafluor647-labeled anti-EpCAM antibody (AF647-EpCAM 324212, Biolegend, US), for $30 \mathrm{~min}$ at room temperature. Subsequently, samples were injected into a BD FACSCanto flow cytometer (BD Biosciences, US) and measurements were plotted as median absorbance for each fluorophore (AF647 and FITC). Absorbance values were normalized to an unstained control.

Viability of isolated cell subpopulations. Enriched SKBR3 cell subpopulations were incubated with $1 / 100$ of near-IR dead cell stain kit (L10119-633 nm excitation, Invitrogen, US) for 90 min at room temperature. Notably, this reactive dye can permeate the membrane of necrotic cells and react with free amines both inside the cell and on the cell surface, resulting in an intense fluorescent red stain. On the contrary, live cells are not stained. After washing, cells were fixed with $4 \%$ formaldehyde solution and incubated with FITC-labeled anti-HER2 antibody for $30 \mathrm{~min}$. Cells were counted by overlaying the bright field, red, and green fluorescent images.

Proliferative capacity of isolated cell subpopulations. Enriched SKBR3 cell subpopulations were fixed with $4 \%$ formaldehyde solution, permeabilized with $0.2 \%$ Triton X and incubated with AF488-labeled anti-Ki-67 antibody (ab154201, Abcam, US) and APC-labeled anti-CK for 2 hours. Notably, Ki-67 is a nuclear protein used to assess the proliferative capacity of cell. It is present during all active phases of cell cycle (G1, $\mathrm{S}, \mathrm{G} 2$, and mitosis) but absent in resting cells (G0). ${ }^{5}$ After washing, the cells were stained with DAPI Prolong Gold reagent. Cells were counted by overlaying the bright field, red, blue, and green fluorescent images.

2D isolation of $\mathrm{CK}^{+} / \mathrm{DAPI} I^{+} / \mathrm{CD}^{-} 5^{-}$cell subpopulations from cancer patient's blood. Patient blood samples were collected with consent prior to prostate or radical 
prostatectomy. The characteristics of these samples are outlined in Table S2. All blood samples were analyzed within few hours of sample collection. A set of prostate cancer patient samples were analyzed using the developed method to determine if this approach would be effective with clinical sample containing a small number of cancer cells and whether different patients would demonstrate different profiles for cancer cell subpopulations. Each patient sample was split, processed, and analyzed using two independent sorting chips, including the Ap2D-CTC chip and a conventional 4-zone chip in which the cancer cells were captured using magnetic nanobeads labeled anti-EpCAM antibody antibody (diameter $50 \mathrm{~nm}$, Miltenyi Biotec Inc., US). ${ }^{6}$ In Ap2D-CTC approach, $1 \mathrm{~mL}$ of the blood sample was centrifuged in a Ficoll tube to isolate the mononuclear cells (CTCs and WBCs). Afterward, the cells were incubated with $50 \mu \mathrm{L}$ of anti-CD15 (Miltenyi Biotec Inc., US), for $30 \mathrm{~min}$ at room temp. Subsequently, the magnetic nanoparticles were separated using a magnetic stand and the supernatant was collected. Second, the supernatant was mixed with $75 \mu \mathrm{M}$ MCE and incubated with 100 $\mu \mathrm{L}$ of $20 \mu \mathrm{M}$ of the EpCAM1 apatmer solution in DPBS for $1 \mathrm{~h}$ at room temp. The mixture was then loaded into the Ap2D-CTC chip. Importantly, the second dimensional capture and release was carried out using magnetic nanoparticles-labeled EGFR specific aptamer (EGFR1-InT) ${ }^{7}$ and AS-EGFR1, respectively. The cell subpopulations retrieved from the sixteen zones were cultured in 12-well plates previously coated with 1 $\mathrm{mL}$ of $100 \mu \mathrm{g} \mathrm{mL}^{-1}$ collagen (Life Technologies, US), over night. After adding the cells to the wells, $1 \mathrm{~mL}$ of DMEM medium (ATCC 30-2002), containing 10\% FBS and $1 \%$ penicillin-streptomycin, was added to each well and the plates were incubated for $48 \mathrm{~h}$ at $37{ }^{\circ} \mathrm{C}$ and $5 \% \mathrm{CO}_{2}$. Afterward, cells were released using $1 \mathrm{mg} \mathrm{mL}^{-1}$ collagenase enzyme (Sigma-Aldrich, US) for $15 \mathrm{~min}$ at $37^{\circ} \mathrm{C}$. The released cells were incubated with $1 \%$ BSA in PBS for 30 min in ice to reduce the nonspecific binding. Subsequently, the cells were fixed with $4 \%$ paraformaldehyde, permeabilized with $0.2 \%$ Triton $X$, and stained with APC-CK, AF488-CD45, and DAPI. Finally, the cells were placed on a glass slide and scanned with fluorescence microscopy.

Table S1. Sequence of the nucleic acids (Integrated DNA Technologies, US), utilized in the experimental setup

\begin{tabular}{|c|c|}
\hline Nucleic acid & Sequence \\
\hline $\mathrm{T}_{10}-\mathrm{EpCAM}^{8}{ }^{8}$ & $\begin{array}{l}\text { Biotin-( }\left(T_{10}\right)-5^{\prime} \text { TGA AGG TTC GTT GTT TCG GTG GGT GTA GAC TCT TTA GAA GAG ATA CAG } \\
\text { ATT TTG GGA ATG 3' }\end{array}$ \\
\hline TEG-EpCAM1 $^{8}$ & $\begin{array}{l}\text { Biotin-(TEG)-5' TGA AGG TTC GTT GTT TCG GTG GGT GTA GAC TCT TTA GAA GAG ATA CAG } \\
\text { ATT TTG GGA ATG 3' }\end{array}$ \\
\hline $\mathrm{T}_{10}-\mathrm{EpCAM}^{\mathrm{g}}$ & 'Biotin-( (T10)-5' AAC AGA GGG ACA AAC GGG GGA AGA TTT GAC GTC GAC GAC A 3' \\
\hline TEG-EpCAM2 ${ }^{9}$ & 'Biotin-(TEG)-5' AAC AGA GGG ACA AAC GGG GGA AGA TTT GAC GTC GAC GAC A 3' \\
\hline
\end{tabular}




\begin{tabular}{|c|c|}
\hline $\mathrm{T}_{10}-\mathrm{EpCAM}^{10}$ & Biotin-( $\left(T_{10}\right)-5^{\prime}$ CAC TAC AGA GGT TGC GTC TGT CCC ACG TTG TCA TGG GGG GTT GGC CTG 3' \\
\hline TEG-EpCAM3 ${ }^{10}$ & $\begin{array}{l}\text { Biotin-(TEG)-5' CAC TAC AGA GGT TGC GTC TGT CCC ACG TTG TCA TGG GGG GTT GGC CTG } \\
3^{\prime}\end{array}$ \\
\hline Cy5-EpCAM1-TEG & $\begin{array}{l}\text { Cy5-5' TGA AGG TTC GTT GTT TCG GTG GGT GTA GAC TCT TTA GAA GAG ATA CAG ATT TTG } \\
\text { GGA ATG 3'-(TEG)-Biotin }\end{array}$ \\
\hline EpCAM1 & $\begin{array}{l}\text { Biotin-5' TGA AGG TTC GTT GTT TCG GTG GGT GTA GAC TCT TTA GAA GAG ATA CAG ATT TTG } \\
\text { GGA ATG 3' }\end{array}$ \\
\hline TEG-EpCAM & $\begin{array}{l}\text { Biotin-(TEG)-5' TGA AGG TTC GTT GTT TCG GTG GGT GTA GAC TCT TTA GAA GAG ATA CAG } \\
\text { ATT TTG GGA ATG 3'-(TEG)-Biotin }\end{array}$ \\
\hline TEG-HER2- & $\begin{array}{l}\text { Biotin-(TEG)-5' AAC CGC CCA AAT CCC TAA GAG TCT GCA CTT GTC ATT TTG TAT ATG TAT } \\
\text { TTG GTT TTT GGC TCT CAC AGA CAC ACT ACA CAC GCA CA 3' }\end{array}$ \\
\hline TEG-HER2-2 $^{\text {T2 }}$ & $\begin{array}{l}\text { Biotin-(TEG)-5' GGG CCG TCG AAC ACG AGC ATG GTG CGT GGA CCT AGG ATG ACC TGA GTA } \\
\text { CTG TCC 3' }\end{array}$ \\
\hline TEG-HER2-3 ${ }^{13}$ & Biotin-(TEG)-5' GCA GCG GTG TGG GGG CAG CGG TGT GGG GGC AGC GGT GTG GGG 3' \\
\hline AS-EpCAM1 & $\begin{array}{l}\text { 5' CAT TCC CAA AAT CTG TAT CTC TTC TAA AGA GTC TAC ACC CAC CGA AAC AAC CAA CCT } \\
\text { TCA 3' }\end{array}$ \\
\hline EpCAM1-PO ${ }_{4}$ & $\begin{array}{l}\text { Biotin-(TEG) 5' TGA AGG TTC GTT GTT TCG GTG GGT GTA GAC TCT TTA GAA GAG ATA CAG } \\
\left.\text { ATT TTG GGA ATG 3'-(PO }{ }_{4}\right)\end{array}$ \\
\hline EpCAM1-InT & $\begin{array}{l}\text { Biotin-(TEG) 5' TGA AGG TTC GTT GTT TCG GTG GGT GTA GAC TCT TTA GAA GAG ATA CAG } \\
\text { ATT TTG GGA ATG (InT) 3' }\end{array}$ \\
\hline HER2-1-InT & $\begin{array}{l}\text { Biotin-(TEG)-5' AAC CGC CCA AAT CCC TAA GAG TCT GCA CTT GTC ATT TTG TAT ATG TAT } \\
\text { TTG GTT TTT GGC TCT CAC AGA CAC ACT ACA CAC GCA CA (InT) 3' }\end{array}$ \\
\hline AS-HER2-1 & $\begin{array}{l}\text { 5' TGT GCG TGT GTA GTG TGT CTG TGA GAG CCA AAA ACC AAA TAC ATA TAC AAA ATG ACA } \\
\text { AGT GCA GAC TCT TAG GGA TTT GGG CGG TT 3' }\end{array}$ \\
\hline EGFR1-InT ${ }^{7}$ & $\begin{array}{l}\text { Biotin-(TEG)-5' TAC CAG TGC GAT GCT CAG TGC CGT TTC TTC TCT TTC GCT TTT TTT GCT } \\
\text { TTT GAG CAT GCT GAC GCA TTC GGT TGA C (InT) 3' }\end{array}$ \\
\hline AS-EGFR1 & $\begin{array}{l}\text { 5' G TCA ACC GAA TGC GTC AGC ATG CTC AAA AGC AAA AAA AGC GAA AGA GAA GAA ACG } \\
\text { GCA CTG AGC ATC GCA CTG GTA 3' }\end{array}$ \\
\hline
\end{tabular}



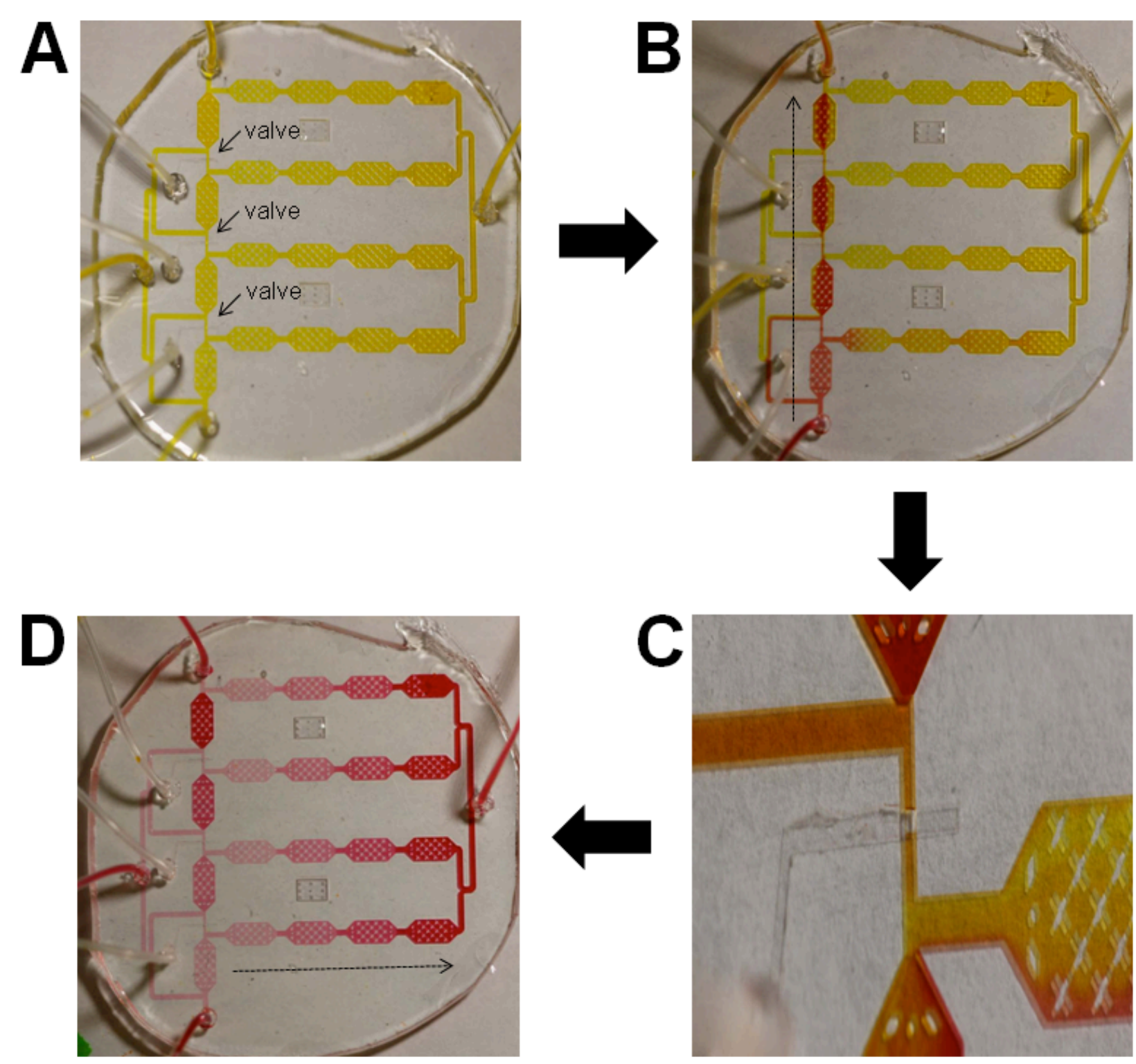

Figure S1. The workstation setup for isolation of cancer cell subpopulations. A. The microfluidic device contains 3 valves, which are used to control the direction of flow. B. The sample is introduced along the first axis of separation to initiate the first dimensional separation, allowing for cell sorting based on the first surface marker. The flow is maintained in this direction by the sheath flow from the lower to the upper port. C. The valves are set to the closed position, diverting the flow to the second direction to initiate the second dimensional separation. D. Flow proceeds in the second direction, allowing for cell sorting based on the second surface marker. 

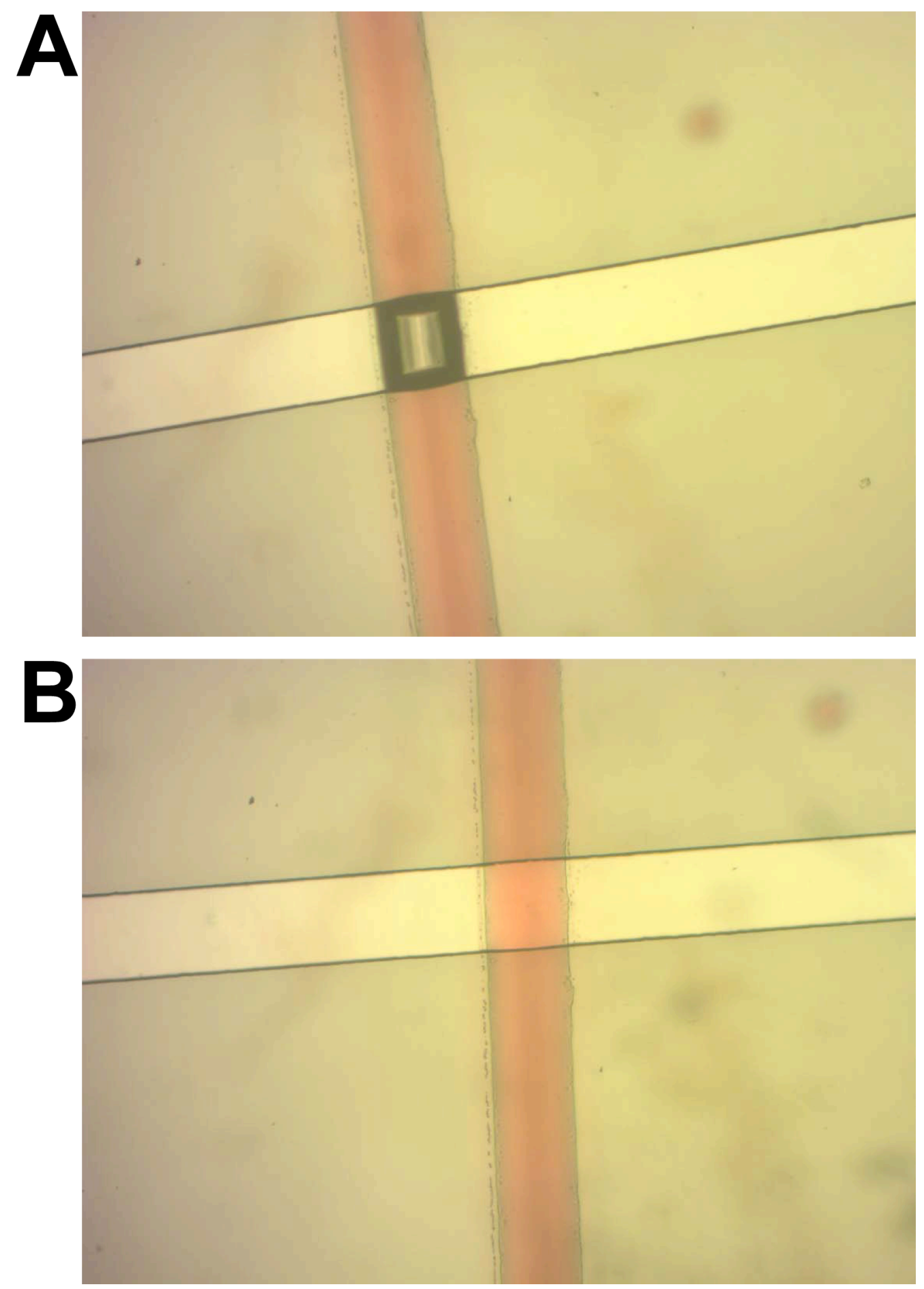

Figure S2. Closed (A) and opened (B) configuration of the valves within the microfluidic device. 


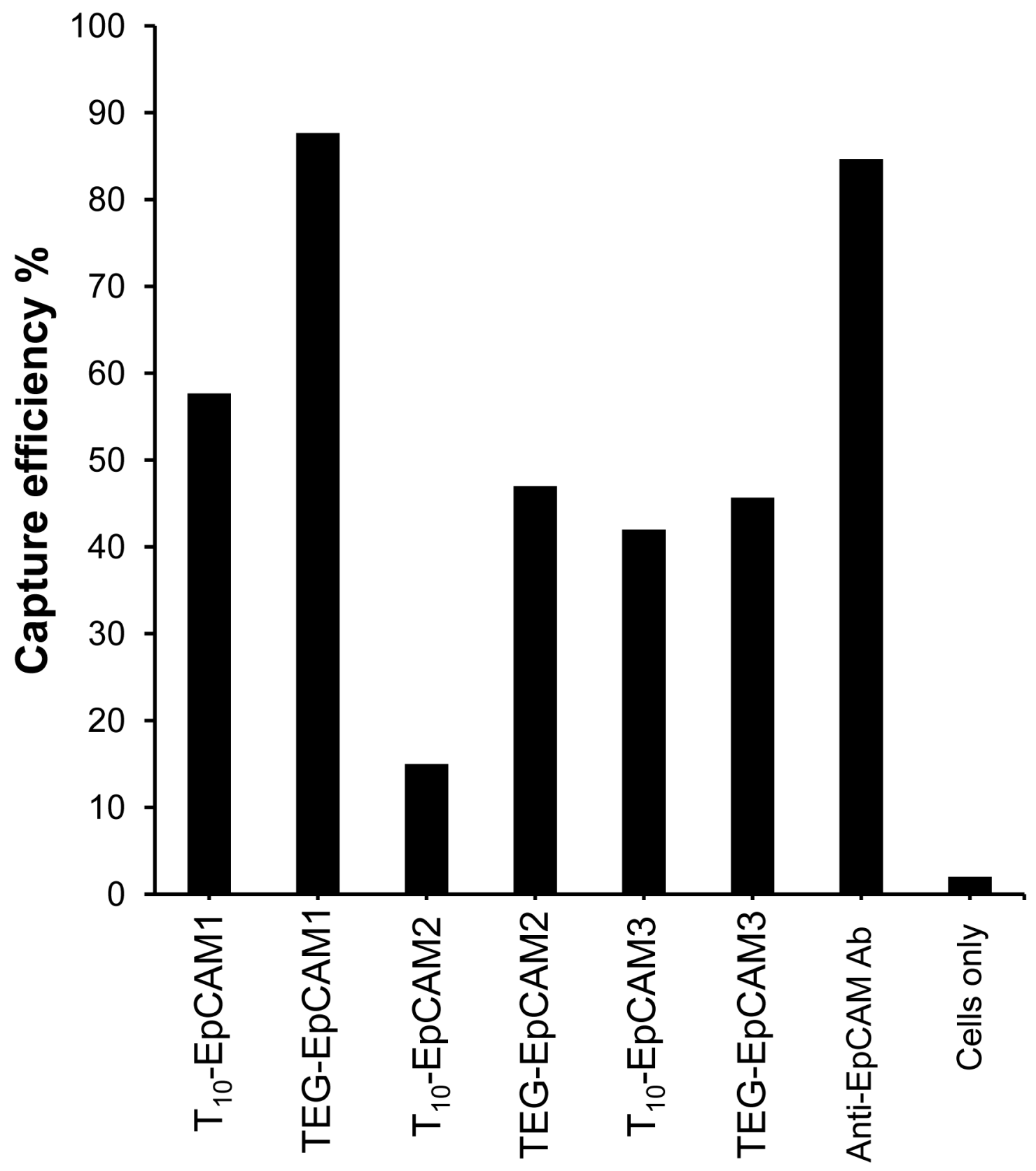

Figure S3. Selection of an EpCAM-specific aptamer with high capture efficiency for EpCAMexpressing cancer cells. The fluidic device was loaded with 1:1 mixture of $\mathrm{VCaP}$ and $\mathrm{U} 937$ cells ( 300 cells $\mathrm{mL}^{-1}$ of each) bound to EpCAM specific aptamers tagged with magnetic nanoparticles at a flow rate of $600 \mu \mathrm{L} \mathrm{min}{ }^{-1}$. An array of magnets was utilized to trap cells with bound nanoparticles. Three EpCAM specific aptamers, including EpCAM1, EpCAM2, and EpCAM3, were tested and each aptamer terminated with a biotin tag through either a $T_{10}$ or TEG spacer. Two control experiments were performed using the anti-EpCAM antibody, instead of the aptamer (positive control) and cells alone (negative control). Captured cells were identified using a triple-stain system, including DAPI, anti-CK, and anti-CD45. Only $\mathrm{CK}^{+} / \mathrm{DAPI} / \mathrm{CD}^{+} 5^{-}$ cells were counted. 


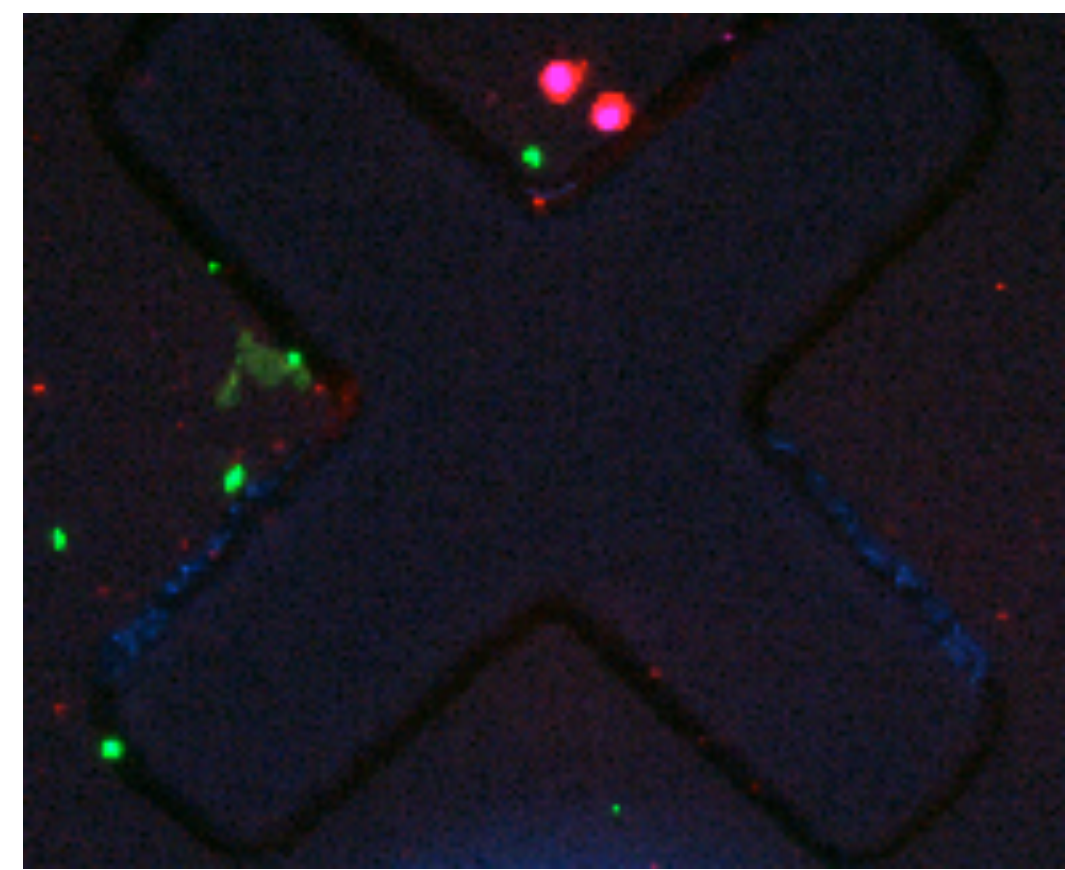

Figure S4. Verification of the binding of EpCAM specific aptamer, EpCAM1 to EpCAM expressing cells. Fluorescence microscope image of the binding between Cy5-labeled EpCAM1 (red) and the cells. Captured cells were identified using two stains only, including DAPI (blue) and alexafluor 488-labeled anti-CD45 (green). 


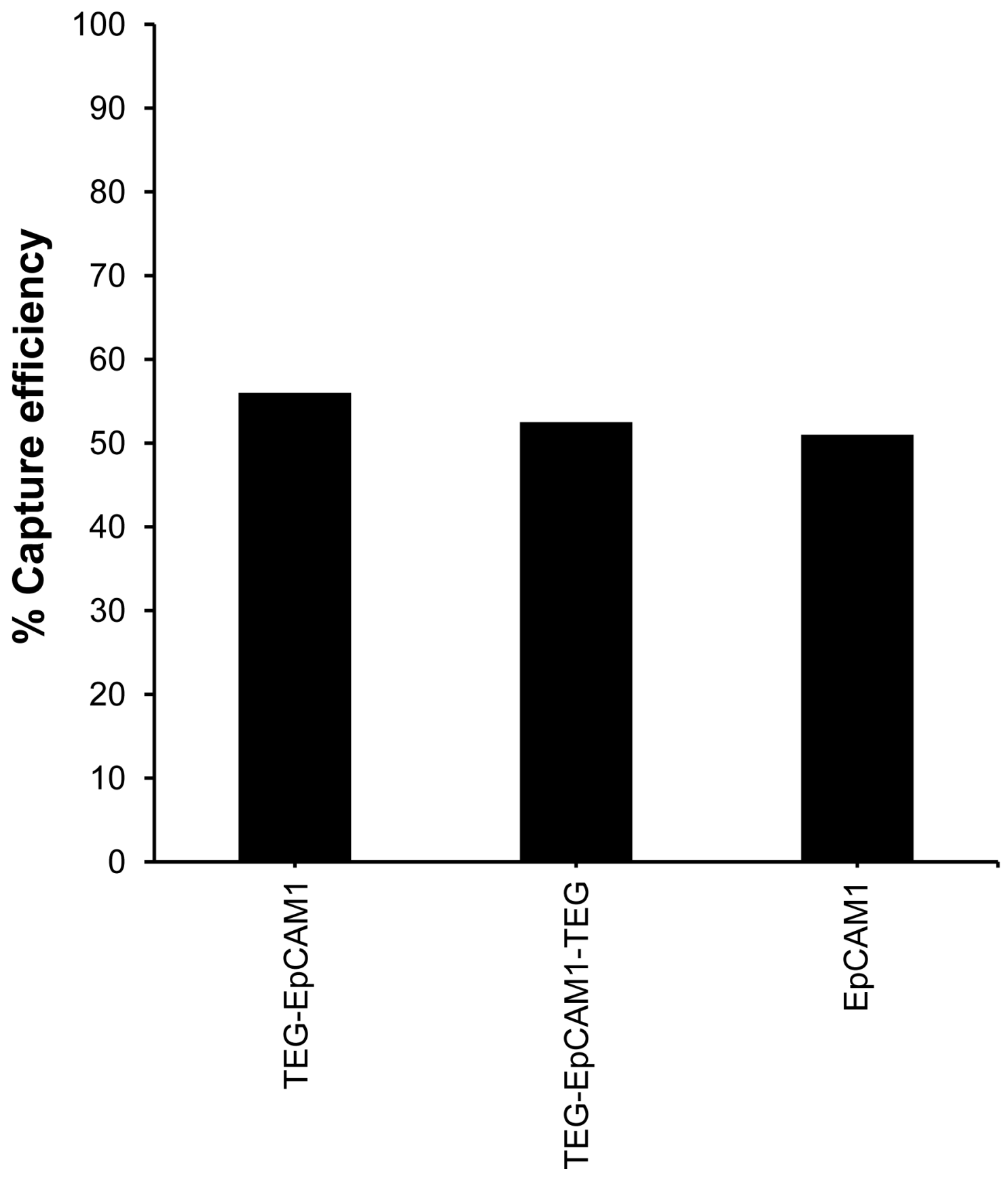

Figure S5. Evaluation of the effect of the spacer on the capture efficiency of EpCAM specific aptamer. The device was loaded with 1:1 mixture of SKBR3 and U937 cells (200 cells mL ${ }^{-1}$ of each) bound to EpCAM specific aptamers tagged with magnetic nanoparticles at a flow rate of $600 \mu \mathrm{L} \mathrm{min}{ }^{-1}$. An array of magnets was utilized to trap cells with bound nanoparticles. The EpCAM1 aptamer terminated either directly with a biotin molecule (no spacer) or with one biotin molecule through a TEG spacer or with two biotin molecules through two TEG spacers at the proximal and distal ends. Captured cells were identified using a triple-stain system, including DAPI, anti-CK, and anti-CD45. Only $\mathrm{CK}^{+} / \mathrm{DAPI} / \mathrm{CD} 45^{-}$cells were counted. 


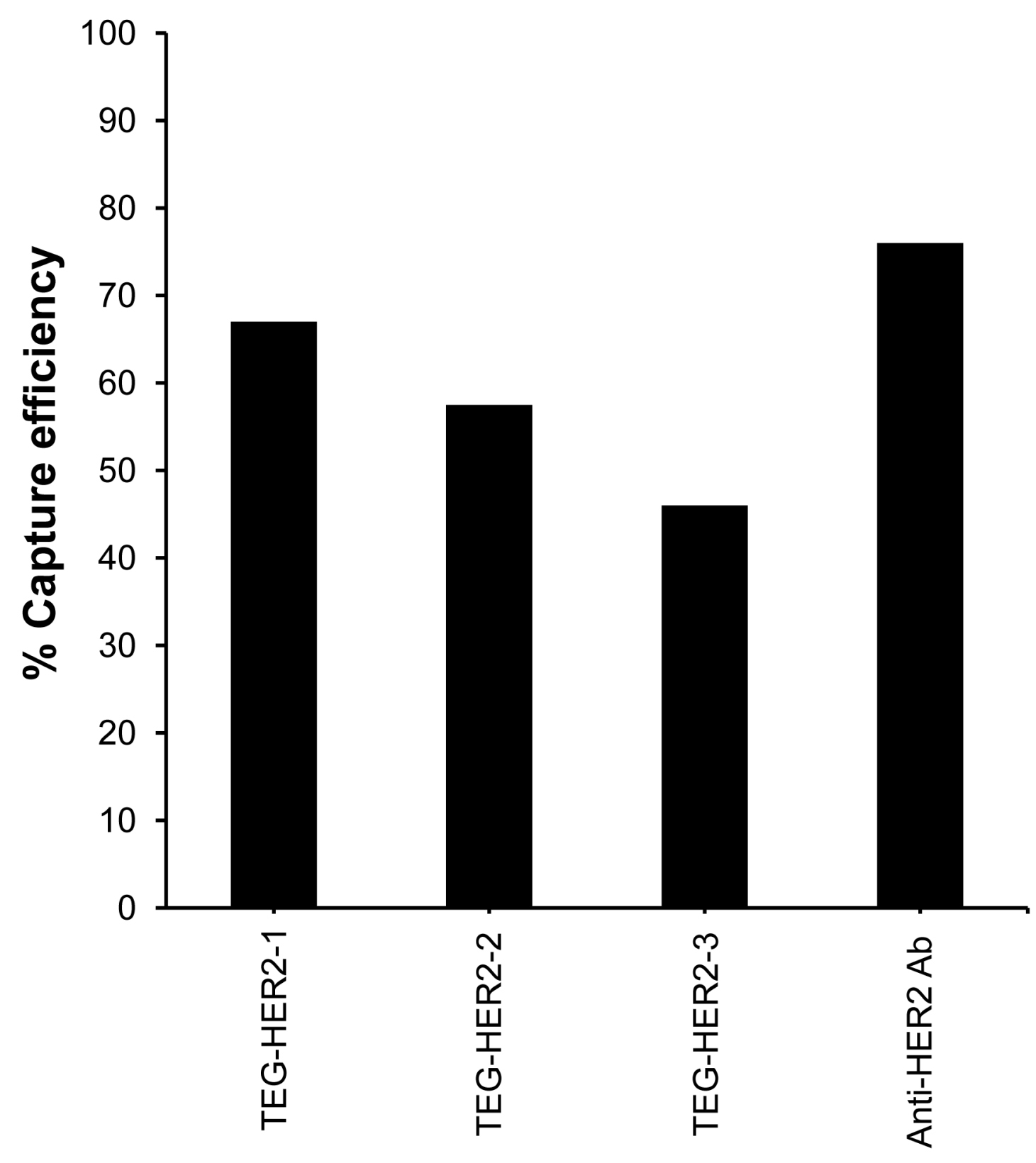

Figure S6. Selection of a HER2 specific aptamer with high capture efficiency for HER2expressing cancer cells. The fluidic device was loaded with 1:1 mixture of SKBR3 and U937 cells (200 cells $\mathrm{mL}^{-1}$ of each) bound to HER2 specific aptamers tagged with magnetic nanoparticles at a flow rate of $600 \mu \mathrm{L} \mathrm{min}{ }^{-1}$. An array of magnets was utilized to trap cells with bound nanoparticles. Three HER2 specific aptamers, including HER2-1, HER2-2, and HER2-3, were tested and each aptamer terminated with a biotin tag through a TEG spacer. A control experiment was performed using the anti-HER-2 antibody, instead of the aptamer (positive control). Captured cells were identified using a triple-stain system, including DAPI, anti-CK, and anti-CD45. Only $\mathrm{CK}^{+} / \mathrm{DAPI}{ }^{+} / \mathrm{CD} 45^{-}$cells were counted. 


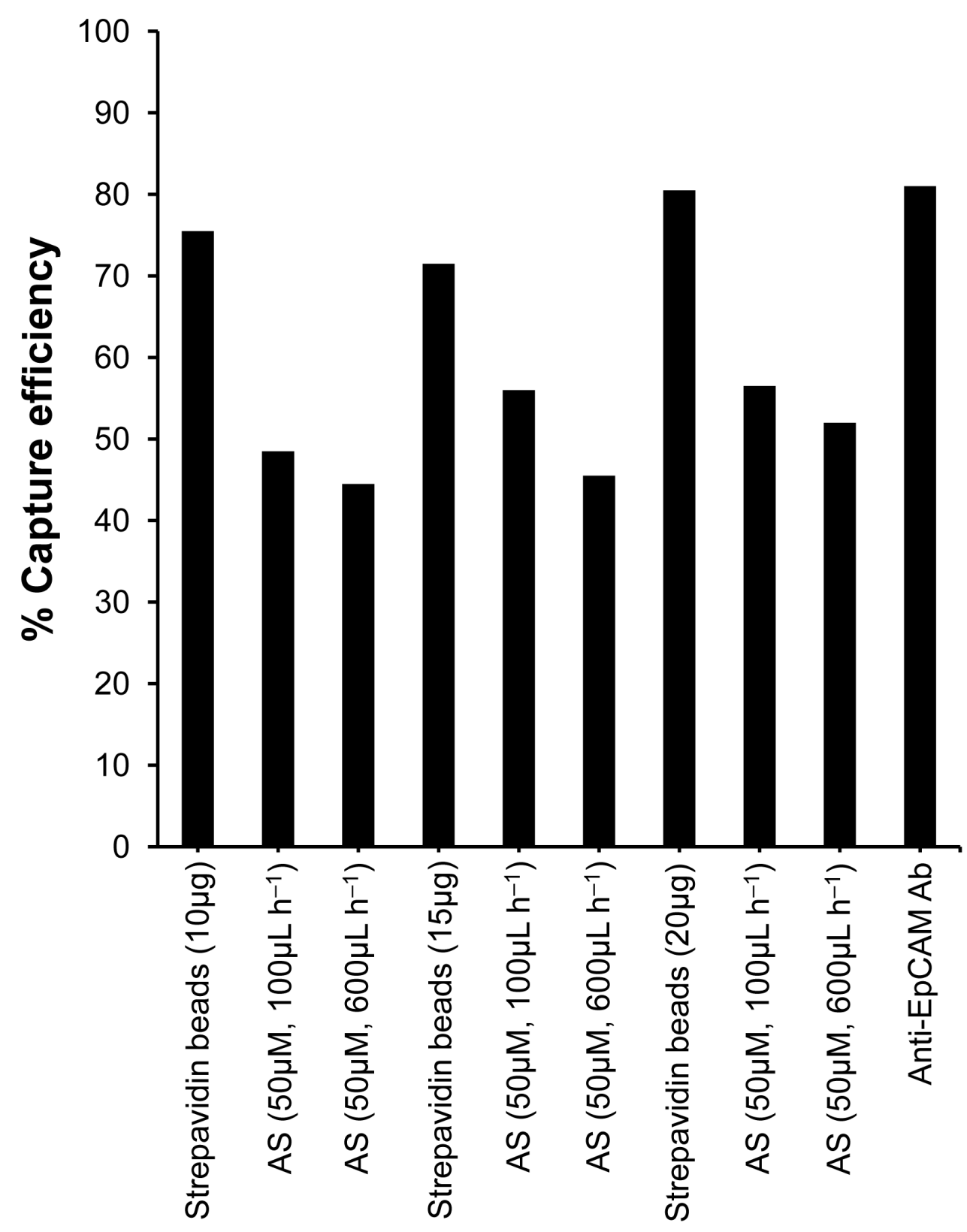

Figure S7. Optimization of the magnetic nanoparticles concentration and cell release format. The device was loaded with 1:1 mixture of $\mathrm{VCaP}$ and U937 cells (200 cells $\mathrm{mL}^{-1}$ each) bound to EpCAM specific aptamers tagged with magnetic nanoparticles at a flow rate of $600 \mu \mathrm{L} \mathrm{min}^{-1}$. An array of magnets was utilized to trap cells with bound nanoparticles. Three different concentrations of the magnetic nanoparticles-tagged EpCAM1 aptamer were tested, including 10,15 , and $20 \mu \mathrm{g}$. Cell release was performed using $100 \mu \mathrm{L}$ of $50 \mu \mathrm{M}$ antisense strand in EDTA/PBS at either a flow rate of $100 \mu \mathrm{L} \mathrm{h}{ }^{-1}$ for $1 \mathrm{~h}$ or $600 \mu \mathrm{L} \mathrm{h}$ for 10 min followed by $30 \mathrm{~min}$ incubation. Subsequently, the cells remaining in the device were stained and counted. One control experiments was performed using the anti-EpCAM antibody instead of the aptamer (positive control). Captured cells were identified using a triple-stain system, including DAPI, anti$\mathrm{CK}$, and anti-CD45. Only $\mathrm{CK}^{+} / \mathrm{DAPI} \mathrm{I}^{+} / \mathrm{CD}^{-} 5^{-}$cells were counted. 

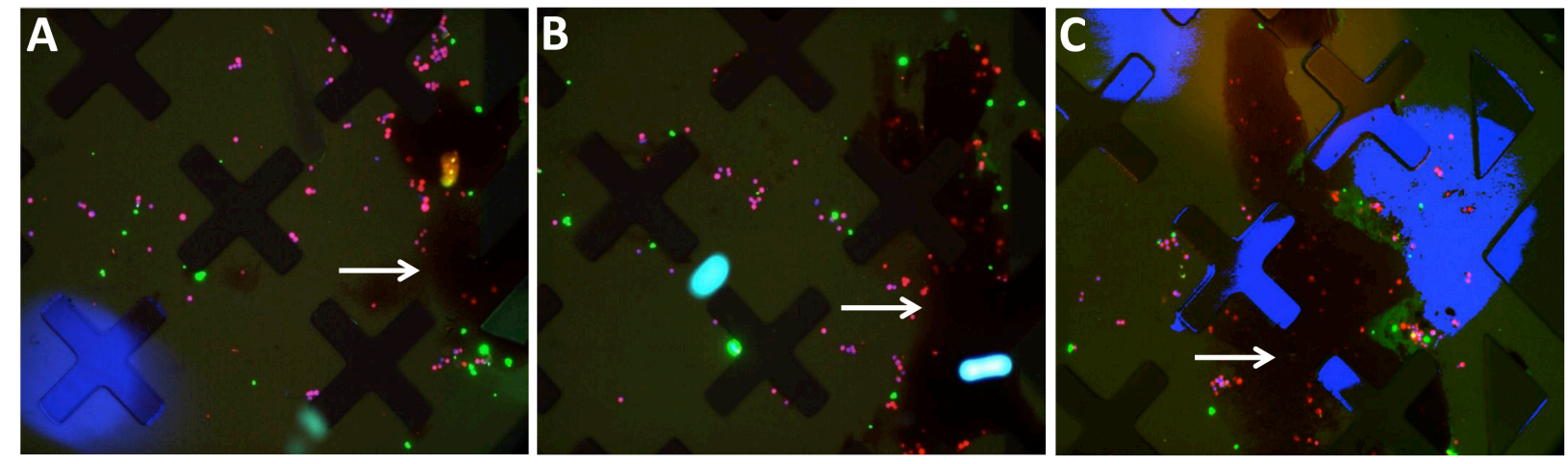

Figure S8. Effect of the magnetic nanoparticles concentration on the cell release efficiency. The device was loaded with 1:1 mixture of $\mathrm{VCaP}$ and U937 cells (200 cells $\mathrm{mL}^{-1}$ each) bound to EpCAM specific aptamers tagged with magnetic nanoparticles at a flow rate of $600 \mu \mathrm{L} \mathrm{min}^{-1}$. An array of magnets was utilized to trap cells with bound nanoparticles. Three different concentrations of the magnetic nanoparticles-tagged EpCAM1 aptamer were tested; including (A) 10, (B) 15, and (C) $20 \mu \mathrm{g}$. Captured cells were identified using a triple-stain system, including DAPI (blue), allophycocyanin-labeled anti-CK (red), and alexafluor 488-labeled antiCD45 (green). Only $\mathrm{CK}^{+} / \mathrm{DAPI}^{+} / \mathrm{CD} 45^{-}$cells were counted. Obviously, increasing the concentration of the magnetic nanobeads caused the cells to become trapped beneath the nanoparticles layer and significantly reduced the release efficiency. 


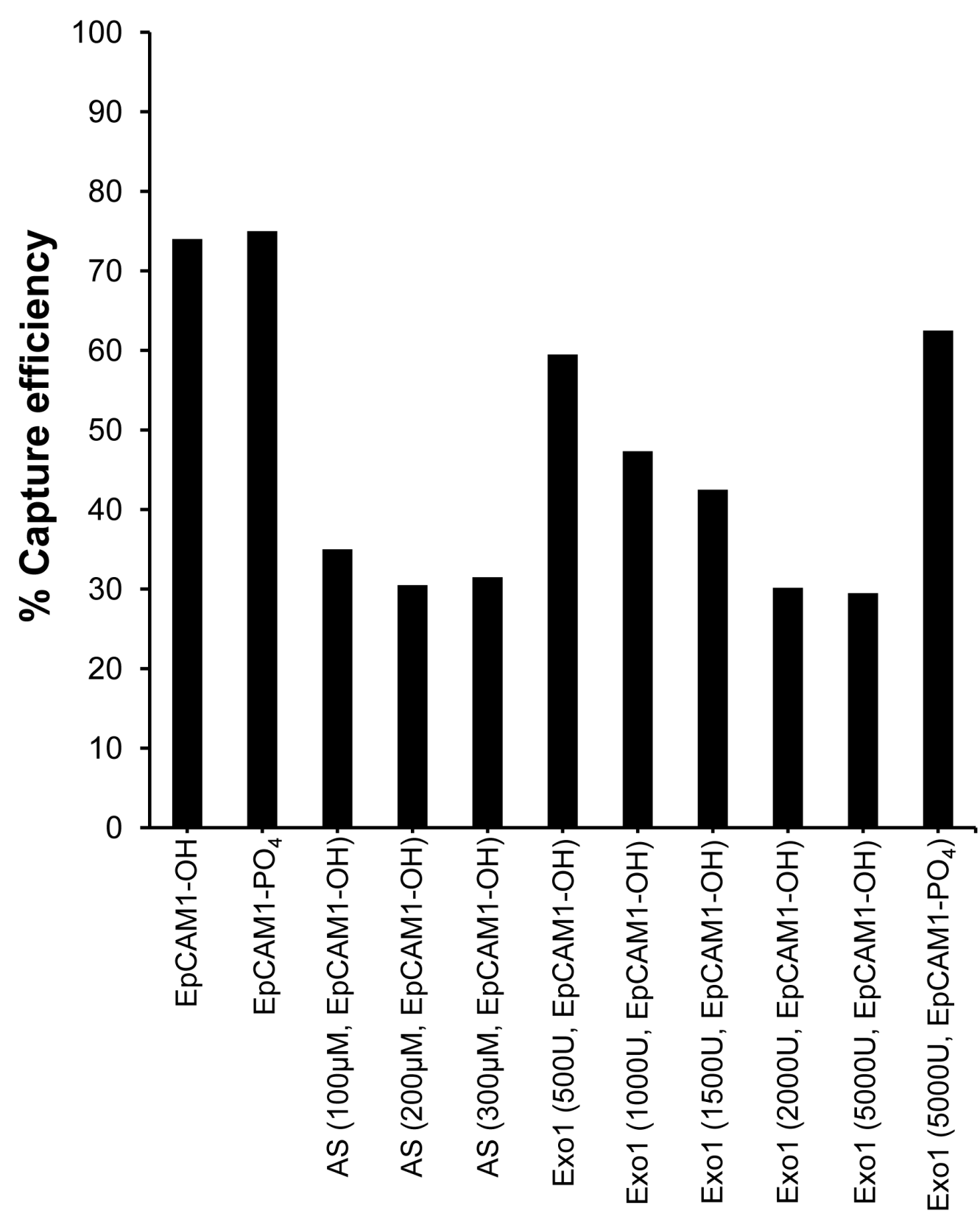

Figure S9. Optimization of releasing agent concentration. The device was loaded with 1:1 mixture of SKBR3 and U937 cells (200 cells each) bound to EpCAM specific aptamers tagged with magnetic nanoparticles. Release of captured SKBR3 cells was carried using $100 \mu \mathrm{L}$ of either 100, 200, or $300 \mu \mathrm{M}$ antisense strand in PBS-EDTA or 500,1000, 1500, 2000, and 5000 $\mathrm{U}$ of exonuclease I (Exo1) in $1 \times$ reaction buffer $(67 \mathrm{mM}$ glycine- $\mathrm{KOH}, 6.7 \mathrm{mM} \mathrm{MgCl}$, $10 \mathrm{mM} \beta$ mercaptoethanol, $\mathrm{pH}$ 9.5). Subsequently, the cells remaining in the device were stained and counted. A control experiment was carried out using the protected aptamer terminated with a phosphate group at the $3^{\prime}$ end. Cell capture was performed at a flow rate of $600 \mu \mathrm{L} \mathrm{min}^{-1}$, whereas cell release was carried out at $600 \mu \mathrm{L} \mathrm{h}^{-1}$ for $10 \mathrm{~min}$ followed by 30 min incubation. An array of magnets was utilized to trap cells with bound nanoparticles. Only $\mathrm{CK}^{+} / \mathrm{DAPI} / \mathrm{CD} 45^{-}$ cells were counted. 


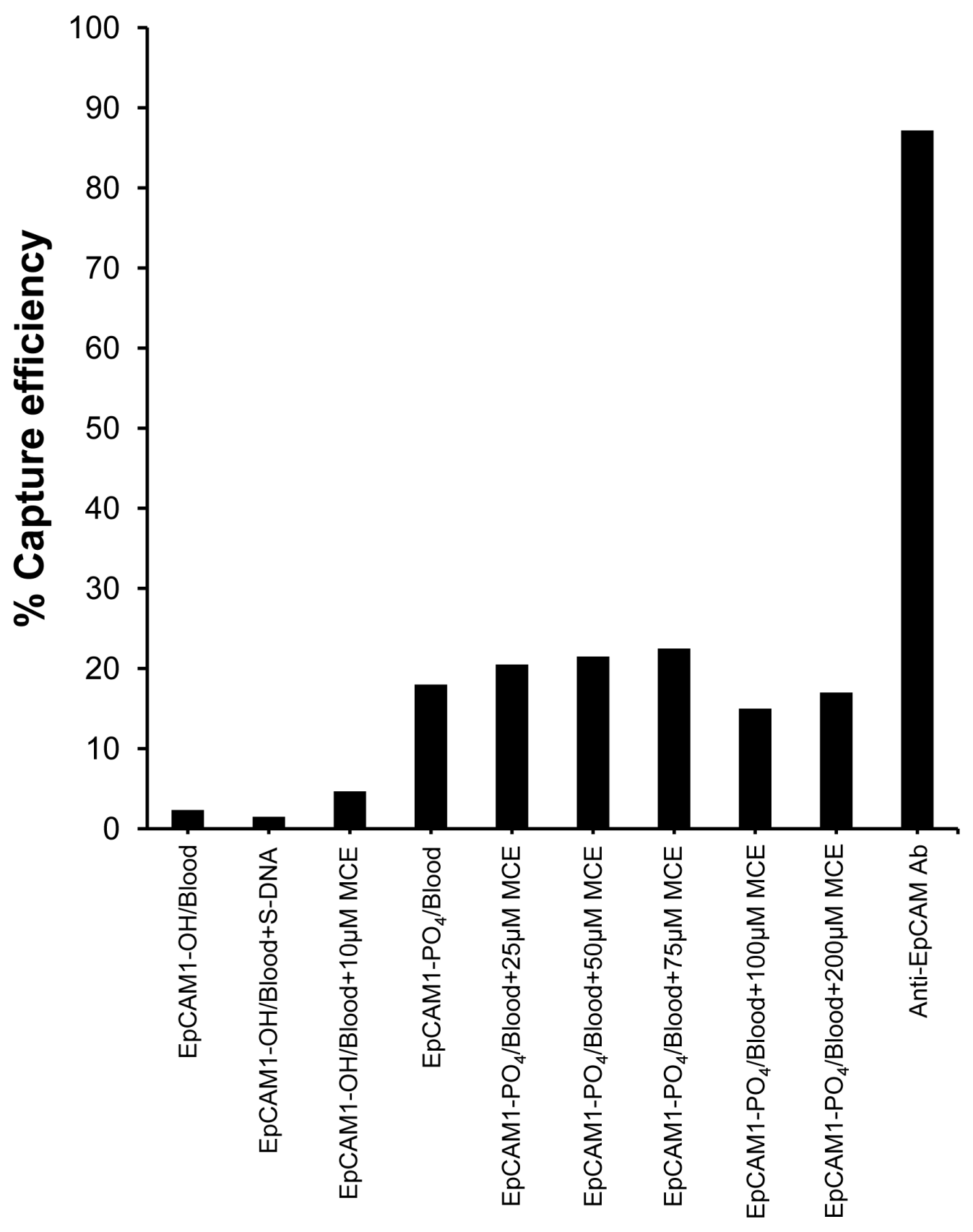

Figure S10. EpCAM1 aptamer based capture of cells from unprocessed whole blood. The device was loaded with 200 SKBR3 cells in blood bound to EpCAM specific aptamers either terminated with $3^{\prime} \mathrm{OH}$ or modified with a $\mathrm{PO}_{4}$ group at the $3^{\prime}$ terminus and tagged with magnetic nanoparticles at the $5^{\prime}$ terminus, at a flow rate of $600 \mu \mathrm{L} \mathrm{min}{ }^{-1}$. An array of magnets was utilized to trap cells with bound nanoparticles. Cells were captured either from blood alone and blood treated with either $2 \mathrm{mg} \mathrm{mL}^{-1}$ salmon DNA or $10,25,50,75,100$, or $200 \mu \mathrm{M}$ mercaptoethanol (MCE). A control experiment was performed using the anti-EpCAM antibody, instead of the aptamer. Captured cells were identified using a triple-stain system, including DAPI, anti-CK, and anti-CD45. Only $\mathrm{CK}^{+} / \mathrm{DAPI} I^{+} / \mathrm{CD} 45^{-}$cells were counted. 


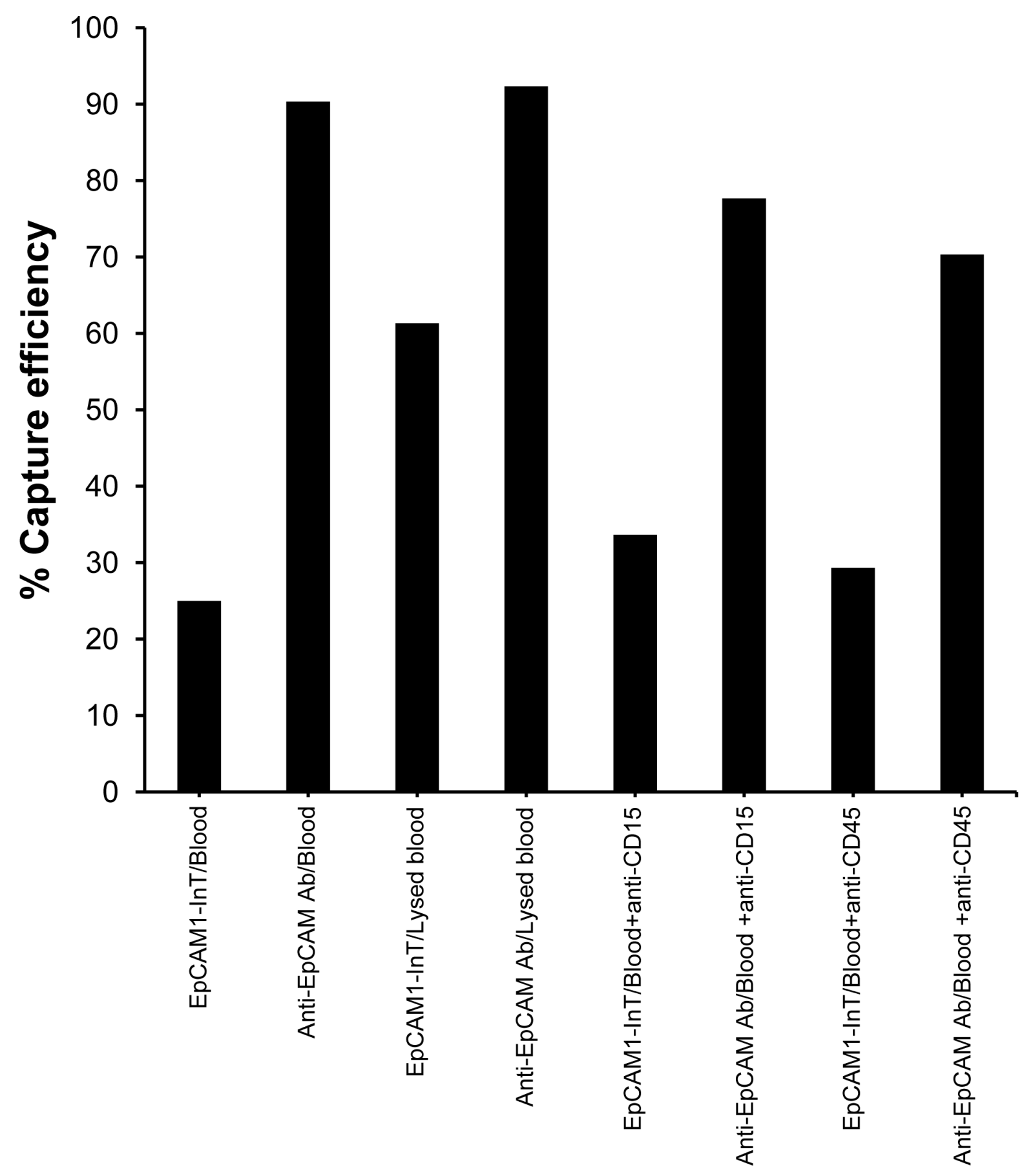

Figure S11. EpCAM1 aptamer based capture of cells from whole, red blood cell-depleted and leukocyte-depleted blood. The device was loaded with 300 SKBR3 cells bound to EpCAM1 aptamer, modified at the $3^{\prime}$ terminus with $\operatorname{InT}$ and tagged with magnetic nanoparticles in whole, red blood cell-depleted, and leukocyte-depleted blood obtained by immunomagentically targeting either the CD15 or CD45. Cell capture was performed at a flow rate of $600 \mu \mathrm{L} \mathrm{min}{ }^{-1}$. An array of magnets was utilized to trap cells with bound nanoparticles. Control experiments were carried out using the magnetic nanoparticles-tagged anti-EpCAM antibody. Only $\mathrm{CK}^{+} / \mathrm{DAPI} / \mathrm{CD} 45^{-}$cells were counted. 


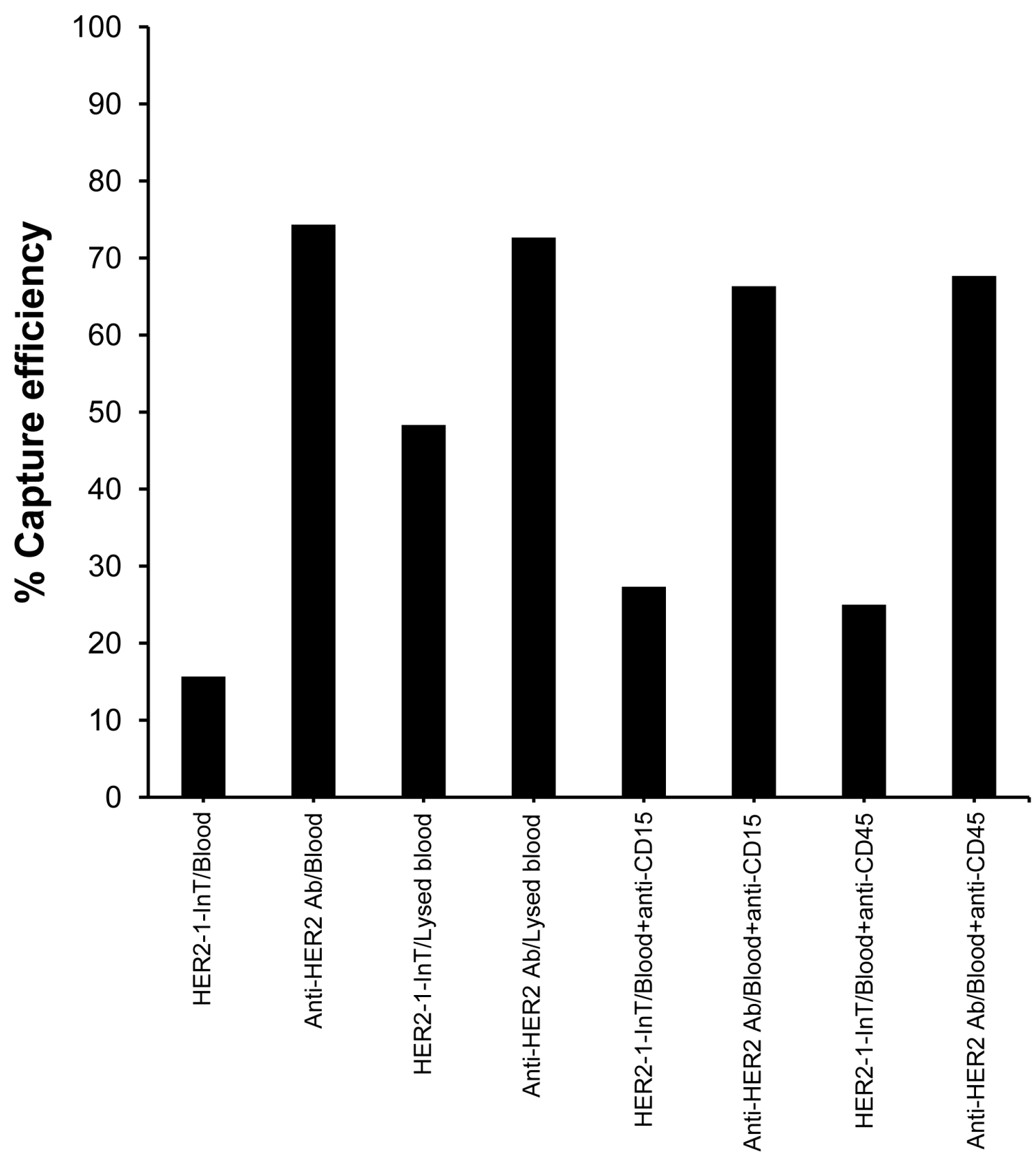

Figure S12. HER2-1 aptamer based capture of cells from whole, red blood cell-depleted and leukocyte-depleted blood. The device was loaded with 300 SKBR3 cells bound to HER2-1 aptamer, modified at the $3^{\prime}$ terminus with $\ln T$ and tagged with magnetic nanoparticles in whole, red blood cell-depleted, and leukocyte-depleted blood obtained by immunomagentically targeting either the CD15 or CD45. Cell capture was performed at a flow rate of $600 \mu \mathrm{L} \mathrm{min}{ }^{-1}$. An array of magnets was utilized to trap cells with bound nanoparticles. Control experiments were carried out using the magnetic nanoparticles-tagged anti-HER2 antibody. Only $\mathrm{CK}^{+} / \mathrm{DAPI}^{+} / \mathrm{CD} 45^{-}$cells were counted. 


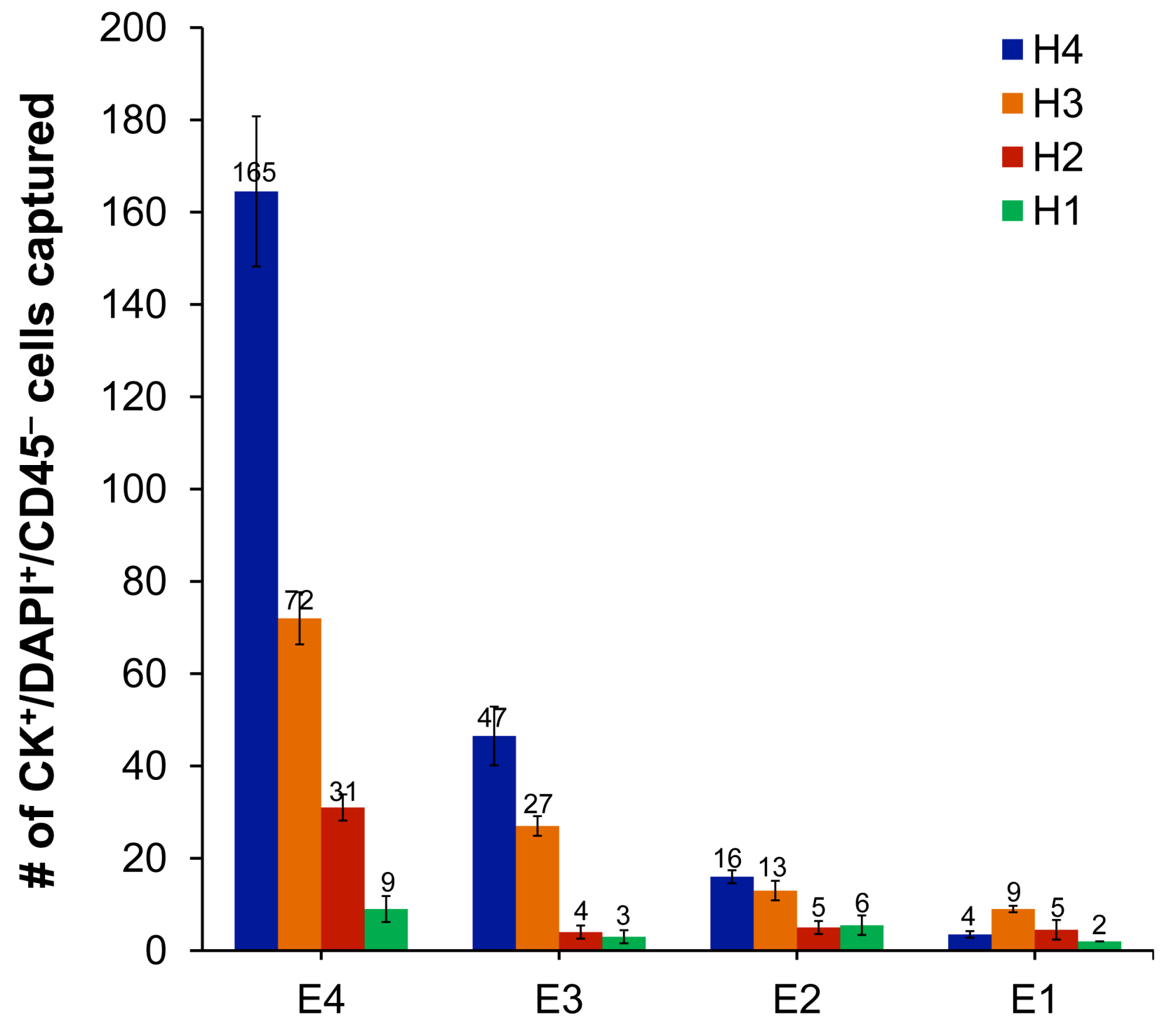

Figure S13. Aptamer mediated 2D isolation of sixteen cell subpopulations from SKBR3 cells. First, 1000 cells were tagged with magnetic nanoparticles labeled EpCAM1 aptamer and captured in the fluidic device according to their EpCAM expression level. Subsequently, E4, E3, E2, and E1 subpopulations were captured in zones I, II, III, and IV, respectively. After releasing the cells using AS-EPCAM1, they were tagged with magnetic nanoparticles labeled HER2-1 aptamer. Similarly, H4, H3, H2, and H1 subpopulations were captured in zones I, II, III, and IV, respectively. 


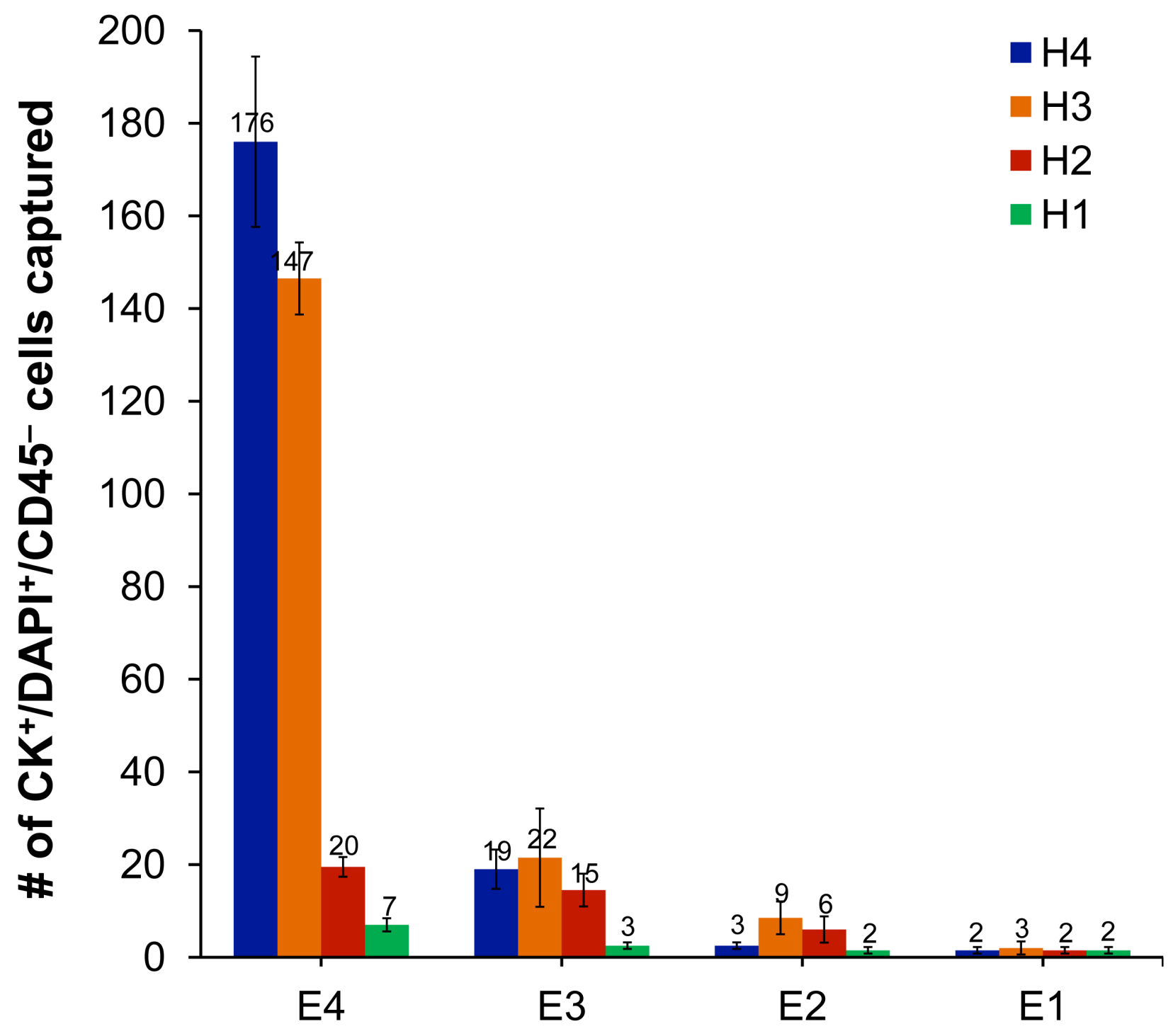

Figure S14. Aptamer mediated 2D isolation of sixteen cell subpopulations from MDA-MB-361 cells. First, 1000 cells were tagged with magnetic nanoparticles labeled EpCAM1 aptamer and captured in the fluidic device according to their EpCAM expression level. Subsequently, E4, E3, E2, and E1 subpopulations were captured in zones I, II, III, and IV, respectively. After releasing the cells using AS-EPCAM1, they were tagged with magnetic nanoparticles labeled HER2-1 aptamer. Similarly, H4, H3, H2, and H1 subpopulations were captured in zones I, II, III, and IV, respectively. 

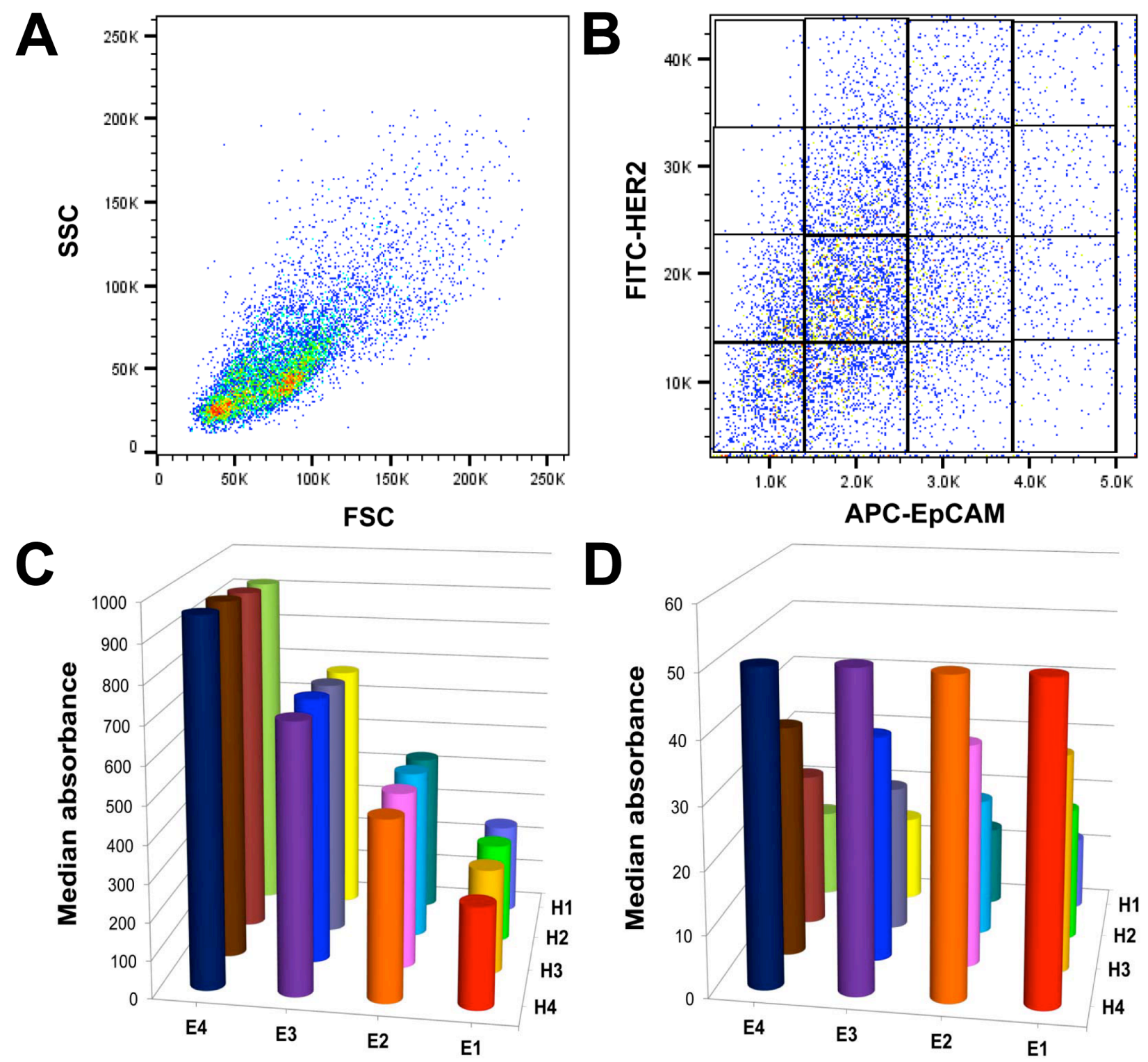

Figure S15. Flow cytometric analysis of SKBR3 subpopulations. Cells were stained with APCEpCAM antibody and FITC-HER2 antibody. (A) Side scatter vs. forward scatter of SKBR3 cell subpopulations. (B) APC vs. FITC intensity of SKBR3 subpopulations. The cell populations were divided into equal zones based on the expression levels of EpCAM and HER2. (C) Median absorbance of APC-EpCAM for each subpopulation. (D) Median absorbance of FITC-HER2 for each subpopulation. The absorbance values were normalized to unstained controls. 


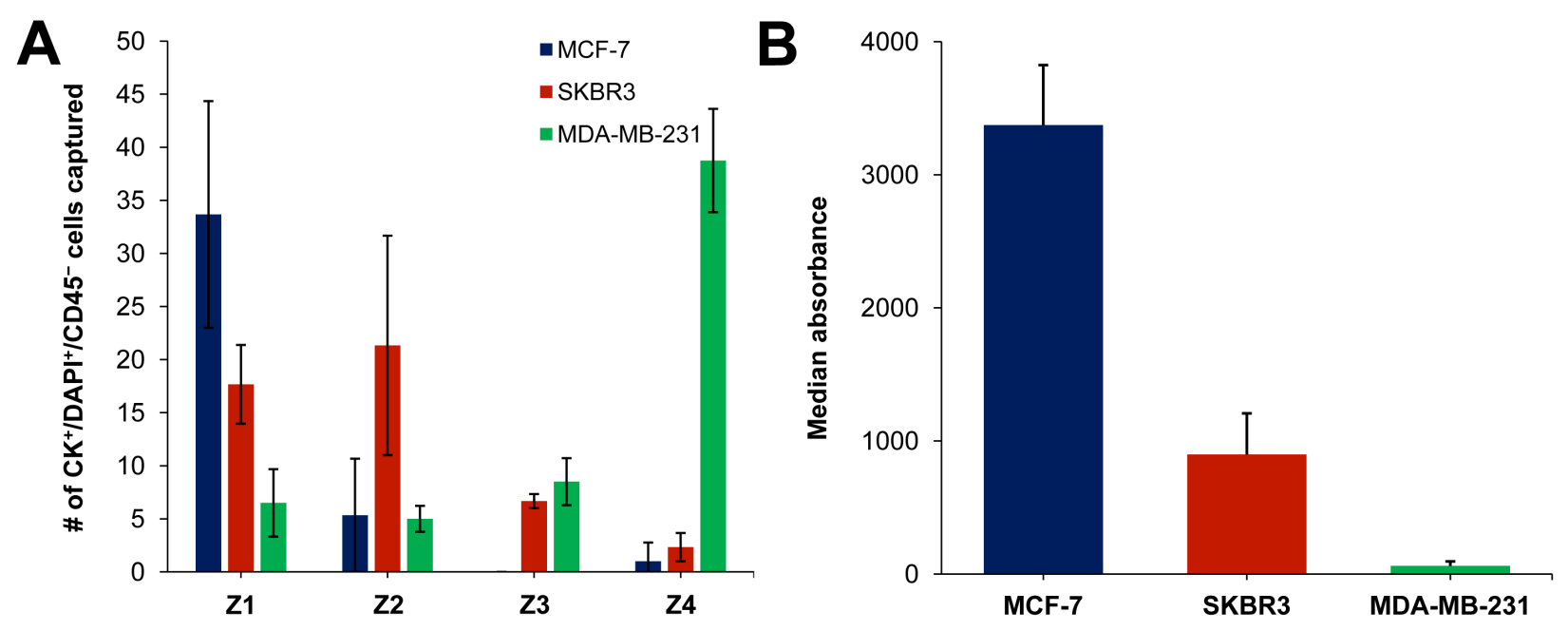

Figure S16. Profiling of three cancer cell lines using Ap2D-CTC chip and flow cytometry. (A) Distribution profile of thee breast cancer cell lines, including MCF7, SKBR3, and MDA-MB-231, in the fluidic chip. Prior to analysis, cells were tagged with EpCAM magnetic beads. Cell capture was performed at a flow rate of $600 \mu \mathrm{L} \mathrm{min}{ }^{-1}$. An array of magnets was utilized to trap cells with bound nanoparticles. Only $\mathrm{CK}^{+} / \mathrm{DAPI} / \mathrm{CD} 45^{-}$cells were counted. (B) Flow cytometric analysis of the EpCAM expression level of the three cell lines. Prior to analysis, cells were tagged with AF647-labeled anti-EpCAM antibody. Median absorbance values were normalized to unstained controls. Number of repeats $=3$. 


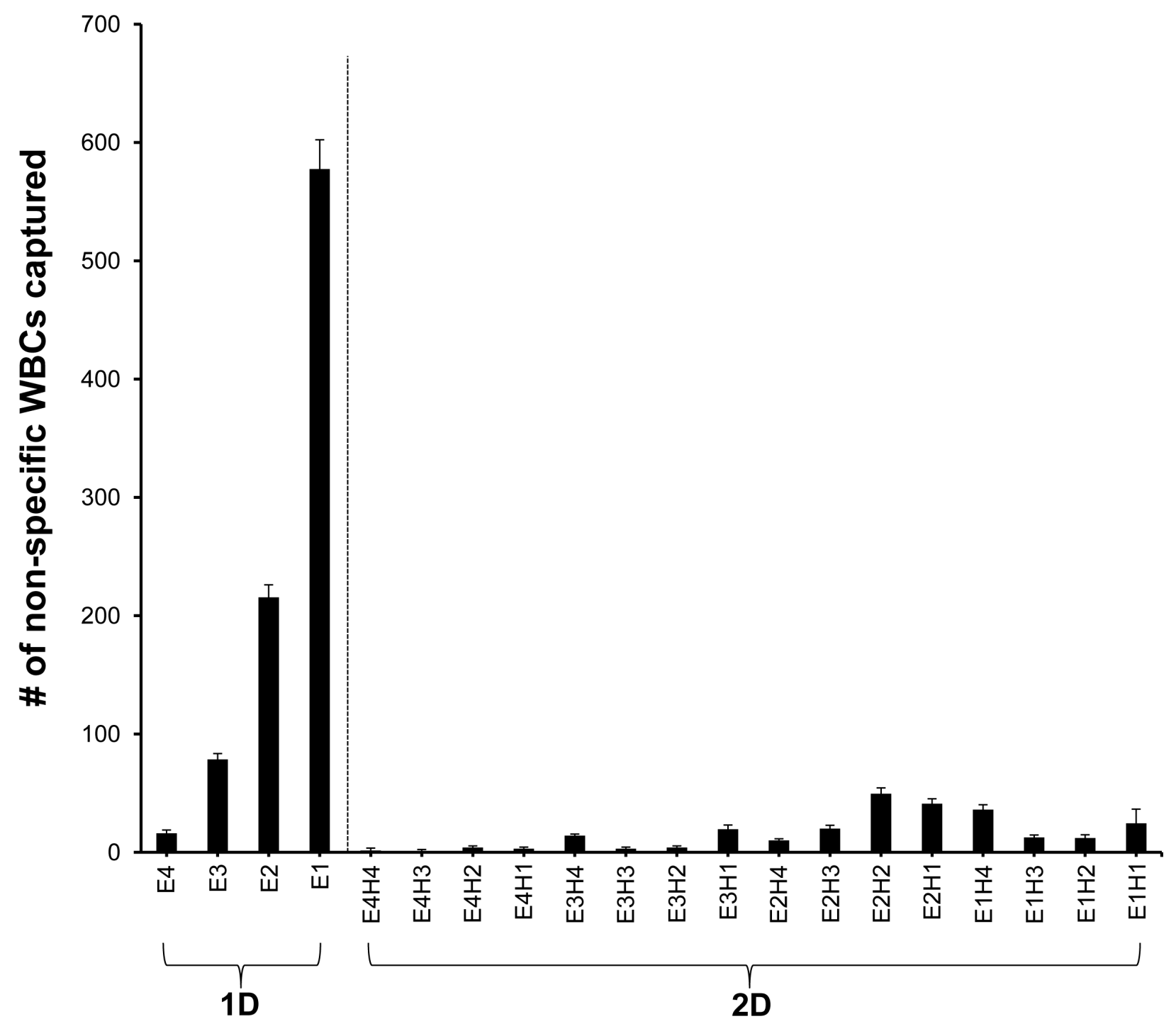

Figure S17. Purity of the cancer cells isolated using Ap2D-CTC chip. Number of the nonspecifically bound white blood cells (WBCs) after the first and second-dimensional isolation of cancer cells from blood. 


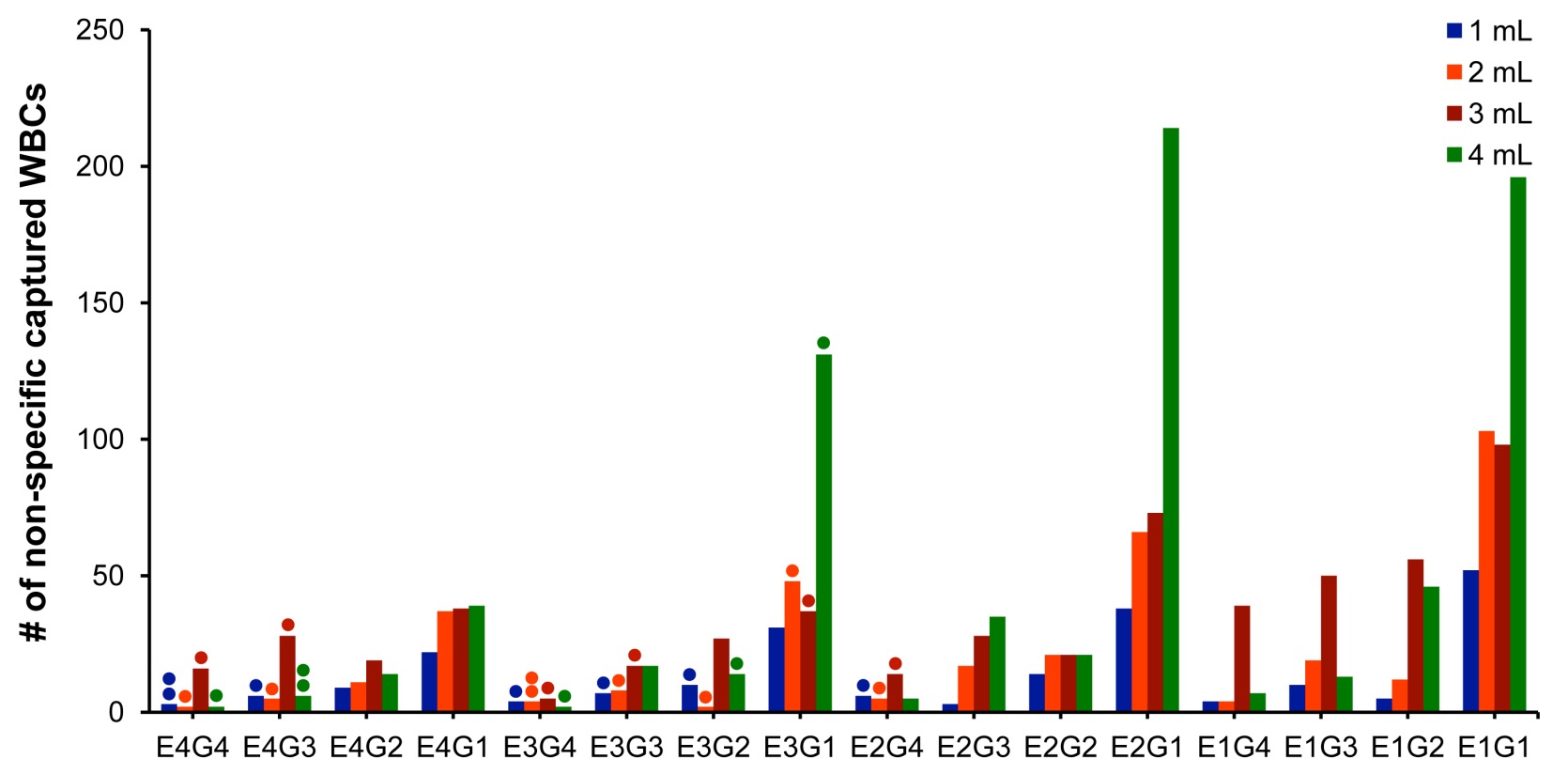

Figure S18. Specificity of the Ap2D-CTC chip. Several volumes of blood $(1,2,3$, and $4 \mathrm{~mL})$ were spiked with $10 \mathrm{VCaP}$ cells. The red blood cells were removed with Ficoll method and the white blood cells were depleted using anti-CD15 tagged magnetic beads. The VCaP cells were captured using magnetic nanoparticles-tagged EpCAM1 aptamer and EGFR1 aptamer in the first and second-dimensional runs, respectively. The number of non-specifically captured leukocytes is shown in the y-axis. The captured VCaP cells are shown as circles (blue for $1 \mathrm{~mL}$, orange for $2 \mathrm{~mL}$, red for $3 \mathrm{~mL}$, and green for $4 \mathrm{~mL}$ blood). 


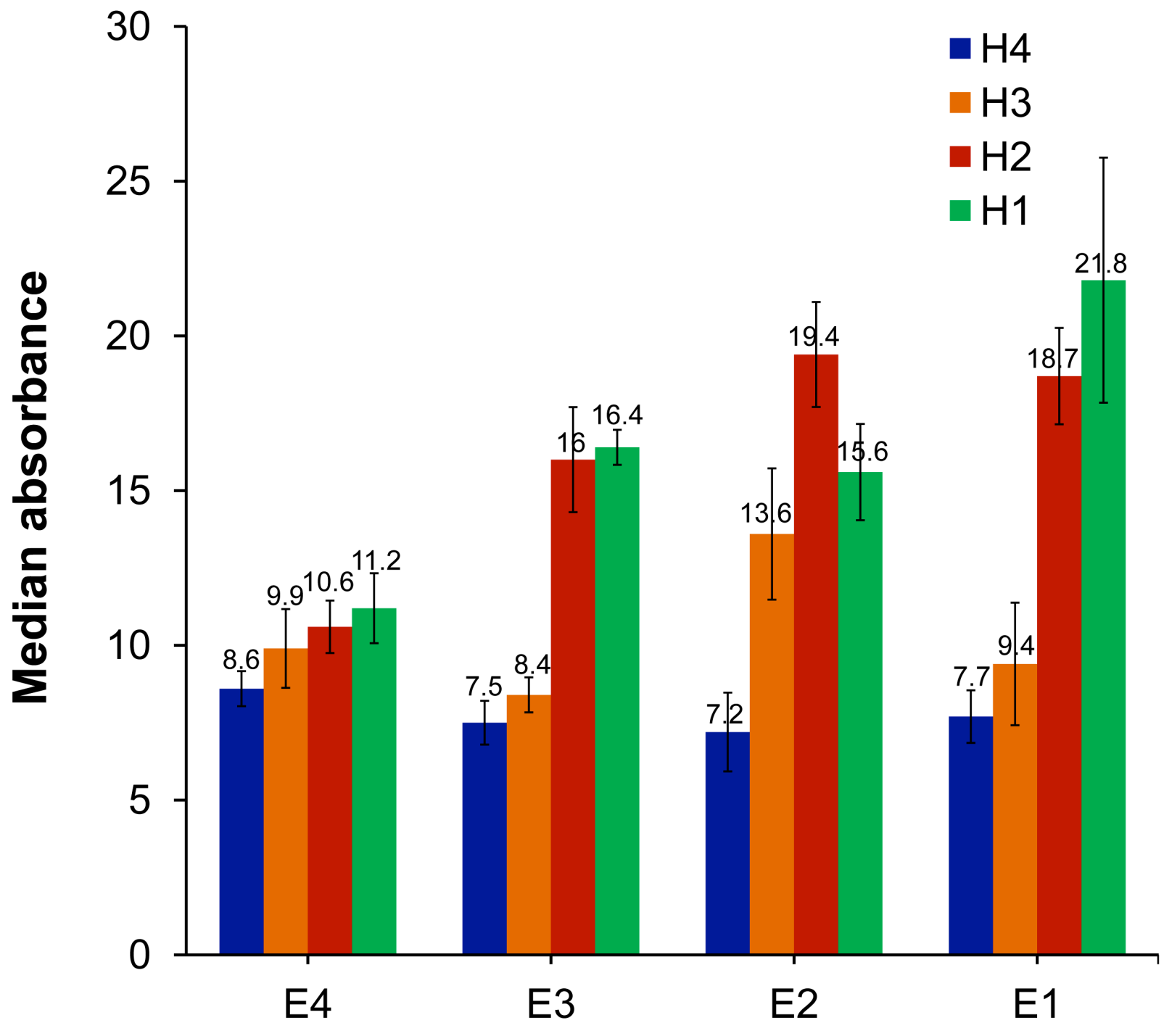

Figure S19. Flow cytometric analysis of the collagen content of isolated cell subpopulations. Sixteen cell subpopulations isolated from the SKBR3 cell line were cultured on 12-well plates previously coated with $1 \mathrm{~mL}$ of $100 \mu \mathrm{g} \mathrm{mL}^{-1}$ FITC-collagen, in the presence of $1 \mathrm{~mL}$ of McCoy's Medium Modified containing 10\% FBS and 1\% penicillin-streptomycin for $48 \mathrm{~h}$ at $37{ }^{\circ} \mathrm{C}$ and $5 \%$ $\mathrm{CO}_{2}$. Samples were analyzed with flow cytometry and the absorbance values were normalized to the unstained control. 


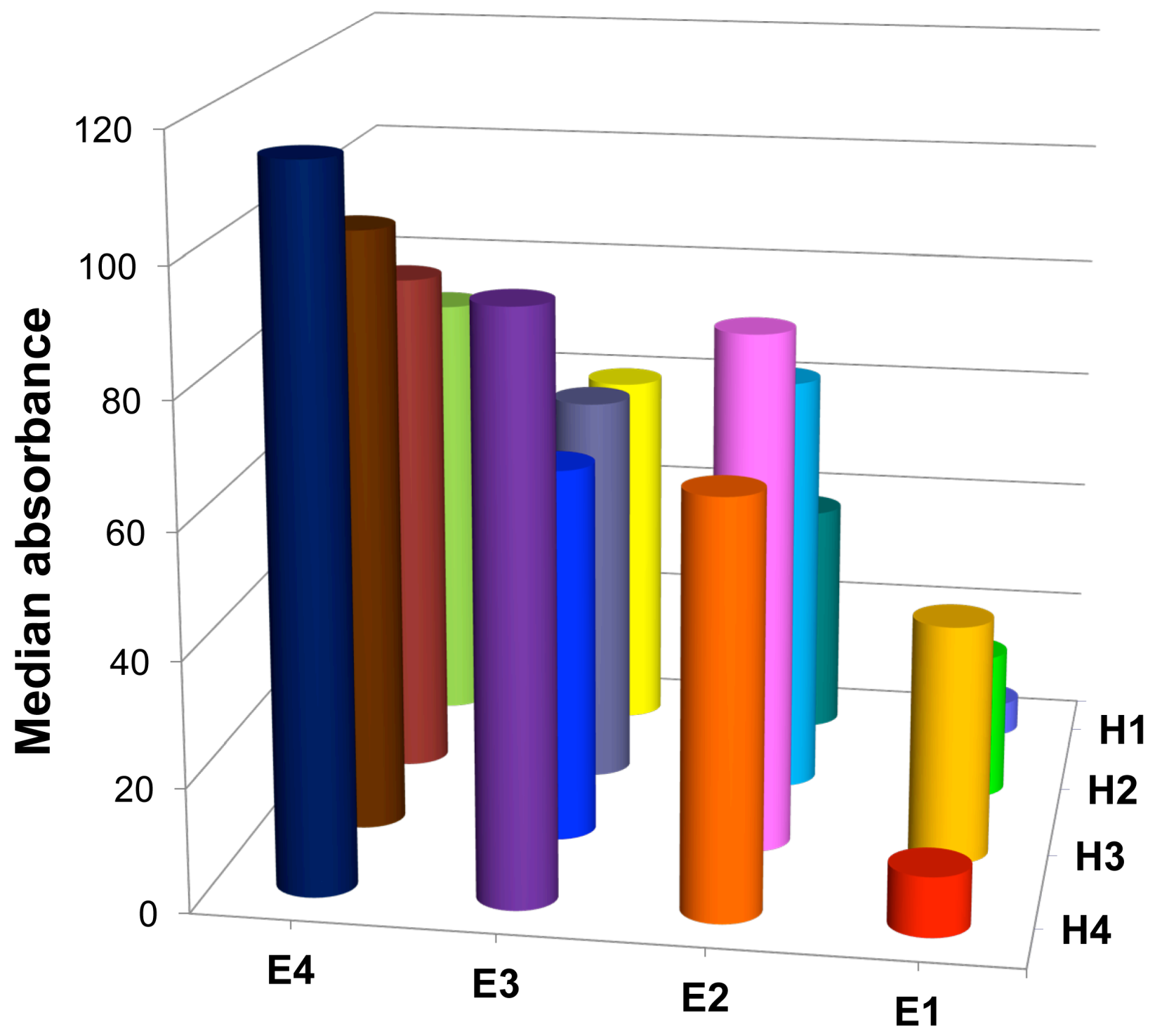

Figure S20. Flow cytometric analysis of the EpCAM expression level of isolated cell subpopulations. Sixteen cell subpopulations isolated from the SKBR3 cell line were cultured on 12 -well plates previously coated with $1 \mathrm{~mL}$ of $100 \mu \mathrm{g} \mathrm{mL}^{-1}$ collagen, in the presence of $1 \mathrm{~mL}$ of McCoy's Medium Modified containing 10\% FBS and 1\% penicillin-streptomycin for $48 \mathrm{~h}$ at $37^{\circ} \mathrm{C}$ and $5 \% \mathrm{CO}_{2}$. Prior to analysis, enriched subpopulations were fixed with $4 \%$ formaldehyde and incubated with AF647 labeled anti-EpCAM antibodies for $30 \mathrm{~min}$ at room temperature. 

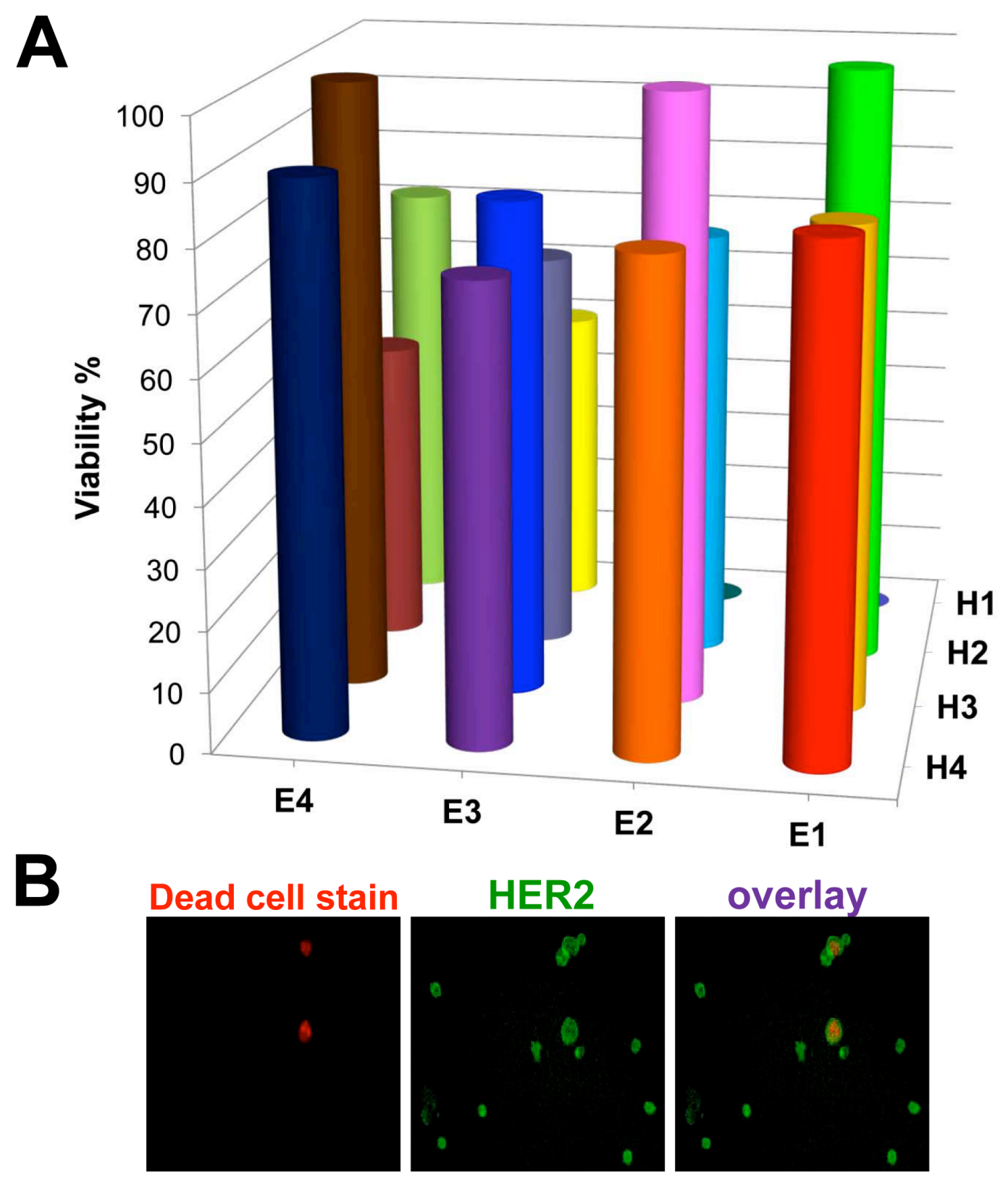

Figure S21. Viability of isolated cell subpopulations. Sixteen cell subpopulations isolated from the SKBR3 cell line were cultured on 12-well plates previously coated with $1 \mathrm{~mL}$ of $100 \mu \mathrm{gL}^{-1}$ collagen, in the presence of $1 \mathrm{~mL}$ of McCoy's Medium Modified containing 10\% FBS and 1\% penicillin-streptomycin for $48 \mathrm{~h}$ at $37{ }^{\circ} \mathrm{C}$ and $5 \% \mathrm{CO}_{2}$. Prior to analysis, Enriched SKBR3 cell subpopulations were incubated with $1 / 100$ of near-IR dead cell stain kit for 90 min at room temperature. After washing, cells were fixed with $4 \%$ formaldehyde solution and incubated with FITC-labeled anti-HER2 antibody for $30 \mathrm{~min}$. Cells were counted by overlaying the bright field, red, and green fluorescent images. The viability \% was determined by dividing the number of live cells by the total cell count. 

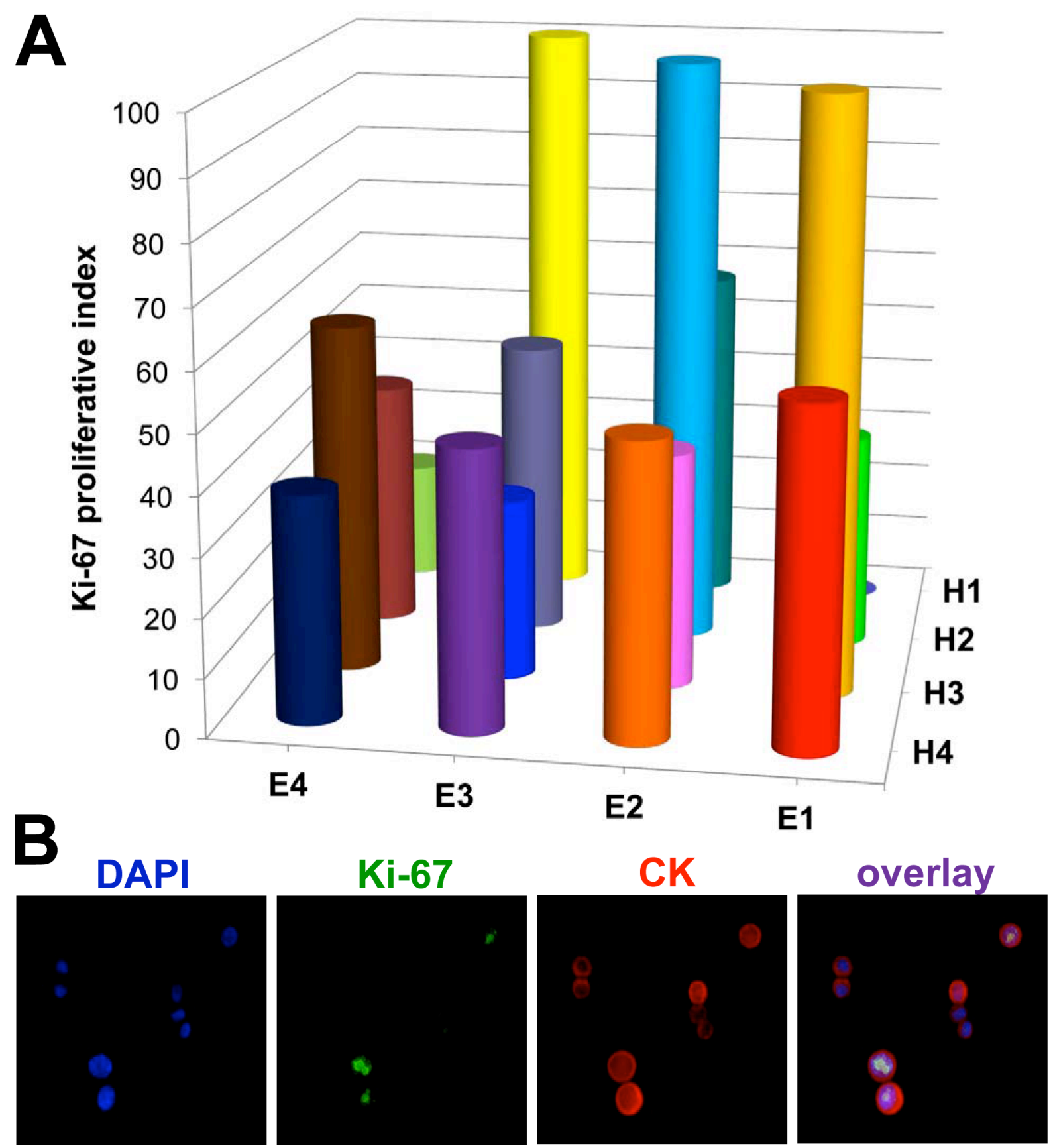

Figure S22. Proliferative capacity of isolated cell subpopulations. Sixteen cell subpopulations isolated from the SKBR3 cell line were cultured on 12-well plates previously coated with $1 \mathrm{~mL}$ of $100 \mu \mathrm{g} \mathrm{mL}{ }^{-1}$ collagen, in the presence of $1 \mathrm{~mL}$ of McCoy's Medium Modified containing $10 \%$ FBS and $1 \%$ penicillin-streptomycin for $48 \mathrm{~h}$ at $37{ }^{\circ} \mathrm{C}$ and $5 \% \mathrm{CO}_{2}$. Prior to analysis, enriched subpopulations were fixed with $4 \%$ formaldehyde solution, permeabilized with $0.2 \%$ Triton $X$ and incubated with AF488-labeled anti-Ki-67 antibody and APC-labeled anti-CK for 2 hours. After washing, the cells were stained with DAPI Prolong Gold reagent. The Ki-67 proliferative index was calculated by dividing the Ki-67 positive cells by the total cell count. 


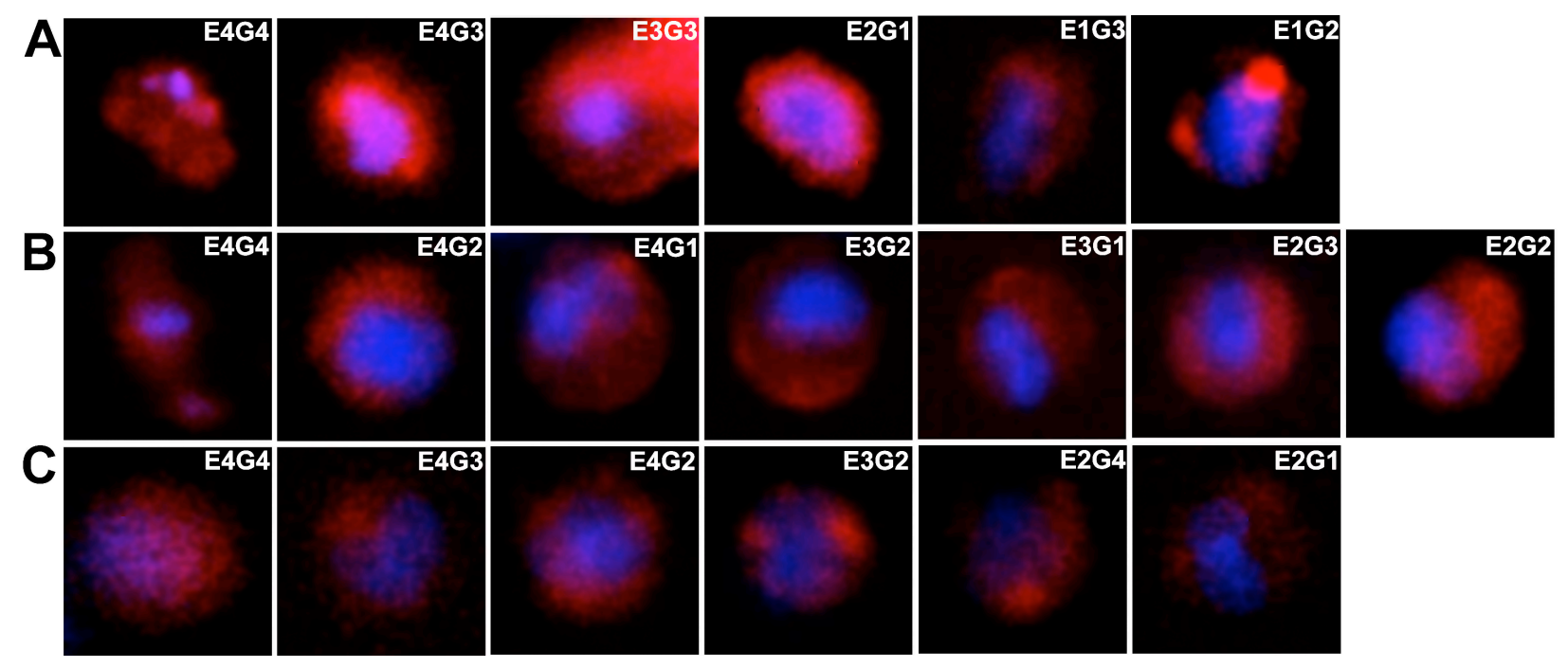

Figure S23. Fluorescence microscope images of the isolated $\mathrm{CK}^{+} / \mathrm{DAPI} / \mathrm{CD} 45^{-}$cell subpopulations from prostate cancer patient's blood. Cell subpopulations were isolated from three prostate cancer patient blood samples, including A. study ID\#5, B. study ID\#16, and C. study ID\#32. The isolated subpopulations were cultured on 12-well plates previously coated with $1 \mathrm{~mL}$ of $100 \mu \mathrm{g} \mathrm{mL}^{-1}$ collagen, in the presence of $1 \mathrm{~mL}$ of DMEM Medium containing $10 \%$ FBS and $1 \%$ penicillin-streptomycin for $48 \mathrm{~h}$ at $37{ }^{\circ} \mathrm{C}$ and $5 \% \mathrm{CO}_{2}$. Prior to analysis, cells were released using $1 \mathrm{mg} \mathrm{mL}^{-1}$ collagenase enzyme for $15 \mathrm{~min}$ at $37^{\circ} \mathrm{C}$. The released cells were incubated with $1 \%$ BSA in PBS for $30 \mathrm{~min}$ in ice to reduce the nonspecific binding. Subsequently, the cells were fixed with $4 \%$ paraformaldehyde, permeabilized with $0.2 \%$ Triton $\mathrm{X}$, and stained with APC-CK, AF488-CD45, and DAPI. 


\section{REFERENCES}

(1) Miltenyi, S.; Muller, W.; Weichel, W.; Radbruch, A. Cytometry 1990, 11, 231-8.

(2) Colombo, M.; Carregal-Romero, S.; Casula, M. F.; Gutierrez, L.; Morales, M. P.; Bohm, I. B.; Heverhagen, J. T.; Prosperi, D.; Parak, W. J. Chem Soc Rev 2012, 41, 4306-34.

(3) Mirkin, C. A.; Letsinger, R. L.; Mucic, R. C.; Storhoff, J. J. Nature 1996, 382, 607-9.

(4) Cutler, J. I.; Auyeung, E.; Mirkin, C. A. J Am Chem Soc 2012, 134, 1376-91.

(5) Scholzen, T.; Gerdes, J. J Cell Physiol 2000, 182, 311-22.

(6) Mohamadi, R. M.; Besant, J. D.; Mepham, A.; Green, B.; Mahmoudian, L.; Gibbs, T.; Ivanov, I.; Malvea, A.; Stojcic, J.; Allan, A. L.; Lowes, L. E.; Sargent, E. H.; Nam, R. K.; Kelley, S. O. Angew Chem Int Ed Engl 2015, 54, 139-43.

(7) Wang, D. L.; Song, Y. L.; Zhu, Z.; Li, X. L.; Zou, Y.; Yang, H. T.; Wang, J. J.; Yao, P. S.; Pan, R. J.; Yang, C. J.; Kang, D. Z. Biochem Biophys Res Commun 2014, 453, 681-5.

(8) Jung, Y. K.; Woo, M. A.; Soh, H. T.; Park, H. G. Chem Commun (Camb) 2014, 50, 12329-32.

(9) Kim, J. W.; Kim, E. Y.; Kim, S. Y.; Byun, S. K.; Lee, D.; Oh, K. J.; Kim, W. K.; Han, B. S.; Chi, S. W.; Lee, S. C.; Bae, K. H. Mol Cells 2014, 37, 742-6.

(10) Song, Y.; Zhu, Z.; An, Y.; Zhang, W.; Zhang, H.; Liu, D.; Yu, C.; Duan, W.; Yang, C. J. Anal Chem 2013, 85, 4141-9.

(11) Liu, Z.; Duan, J. H.; Song, Y. M.; Ma, J.; Wang, F. D.; Lu, X.; Yang, X. D. J Transl Med 2 012, 10, 148.

(12) Niazi, J. H.; Verma, S. K.; Niazi, S.; Qureshi, A. Analyst 2015, 140, 243-9.

(13) Phuc, L. T. M.; Phuc, P. V.; Huan, L. Q. Indian Journal of Applied Research 2014, 4, 6466. 